\title{
AS TRIBAL COLLEGES NOS ESTADOS UNIDOS
}

HARRYSON JÚNIO LESSA GONÇALVES ${ }^{1}$

UNESP, BRASIL

https://orcid.org/0000-0001-5021-6852

ANTÔNIO HILÁRIO AGUILERA URQUIZA ${ }^{2}$

UFMS, BRASIL

https://orcid.org/0000-0002-3375-8630

\begin{abstract}
RESUMO: Este artigo tem como objetivo descrever a organização do sistema educacional dos Estados Unidos caracterizando como a rede das Tribal Colleges se estrutura em tal sistema, bem como identificar significados dados a tal rede naquele contexto sociocultural. Trata-se de uma pesquisa documental em que - além de artigos disponíveis sobre a temática - foram utilizados documentos públicos (normativos, informativos e curriculares) da instituição investigada disponivel em seu portal, bem como dados do portal da Fundação Carnegie. A Tribal College investigada dispõe de três dos seus quatro programas de formação voltados para transferências para universidades, onde seus currículos são construidos por meio de tal lógica e, por vezes, deixando em segundo plano a sua missão institucional - este fato se comprova porque os custos dos seus cursos são $85 \%$ menores que os cobrados nas universidades, atraindo alunos para iniciarem seus dois primeiros anos de formação superior nestas instituições.
\end{abstract}

PALAVRAS-CHAVE: community college, educação escolar indígena, educação internacional, educação estadunidense.

ABSTRACT: This article aims to describe the organization of the educational system in the United States, characterizing how the network of Tribal Colleges is structured in this system, as well as identifying meanings given to network in that sociocultural context. It is a documentary research that - besides to articles available on the subject - public documents (normative, informative and curricular) of the investigated institution were used, available on the institution's portal, as well as data from the Carnegie Foundation portal. The investigated Tribal College has three of four training programs aimed at transfers to universities, where their curricula are built using such logic and, sometimes, leaving their institutional mission in the background - this fact is proven because the costs of courses are $85 \%$ less than those charged at universities, attracting students to start their first two years of higher education at these institutions. It is noteworthy that, of the four programs offered by the investigated institution, only one has training focused specifically on indigenous history and culture.

KEYWORDS: community college, indigenous school education, international education, american education.

\footnotetext{
${ }^{1}$ Docente permanente do Programa de Pós-Graduação em Ensino e Processos Formativos (UNESP/FEIS - Ilha Solteira) e do Programa de Pós-Graduação em Educação para a Ciência (UNESP/FC - Bauru). Email: harryson.lessa@unesp.br

${ }^{2}$ Docente permanente do Programa de Pós-Graduação em Antropologia Social de do Programa de PósGraduação em Direitos Humanos, ambos da UFMS. E-mail: hilarioaguilera@gmail.com
} 


\section{Introdução}

De acordo com American Indian Higher Education Consortium (AIHEC, em português: Consórcio de Educação Superior Indígena Americana), as Tribal Colleges (em português: Faculdades Tribais/Indígenas) foram criadas ao longo dos últimos anos em resposta às necessidades de prover educação superior aos indígenas estadunidenses (AIHEC, 1999). Ou seja, são instituições peculiares que combinam a atenção pessoal com a relevância cultural, de modo a encorajar os indígenas estadunidenses - especialmente aqueles que vivem em reservas - a superar as barreiras no ensino superior (AIHEC, 1999). Cabe salientar que tal rede é composta por community colleges (em português: faculdades comunitárias) e universidades indígenas.

O desejo de conhecer sobre as Tribal Colleges surgiu a partir de uma investigação anterior (realizada pelo primeiro autor) - intitulada "Estudo comparativo sobre o ensino de matemática em currículos de educação profissional técnica: Brasil e Estados Unidos" (ocorrida entre os anos de 2015 e 2017 e, também, financiada pela Fundação de Amparo à Pesquisa do Estado de São Paulo - FAPESP3) - cujos objetivos eram ${ }^{4}$ : (i) analisar semelhanças e singularidades da organização dos sistemas de ensino brasileiro e estadunidense, bem como seus marcos legais e arcabouços curriculares, ressaltando as possíveis orientações específicas sobre o ensino de Matemática na formação laboral; (ii) analisar semelhanças e singularidades inerentes às necessidades, dificuldades e estratégias de formação matemática presentes na formação profissional no contexto dos cursos da área da indústria das instituições pesquisadas.

Naquela ocasião, durante as visitas técnicas realizadas aos Estados Unidos para fins de reconhecimento do sistema de Educação Profissional daquele país, o primeiro autor deparou-se com uma rede de Tribal Colleges (e Universidades) - composta por instituições que, na ocasião, despertaram-lhe interesse em conhecê-las, algo que agora foi possível devido à bolsa de pesquisa no exterior (BPE) - fomentada pela FAPESP5 .

A partir deste contexto, produzimos ${ }^{6}$ o presente artigo visando disseminar tal experiência educacional das Tribal Colleges estadunidenses para a comunidade lusófona com intuito de contribuir com suas pesquisas - especialmente aquelas realizadas no âmbito da Educação Comparada e Internacional ${ }^{7}$. Para tanto, optamos pelo seguinte caminho argumentativo: descrever a organização do sistema educacional dos Estados Unidos caracterizando como a rede das Tribal Colleges se estrutura em tal sistema, bem como identificar significados dados a tal rede naquele contexto sociocultural. Assim, para escrita do artigo - além

\footnotetext{
${ }^{3}$ Disponível em: < https://bv.fapesp.br/pt/bolsas/186964>. Acesso em: 27 jan. 2020.

${ }^{4}$ Resultados desta investigação podem ser encontrados em Gonçalves, Dias e Gonçalves (2018).

5 Bolsa que possibilitou o autor a permanecer nos EUA por três meses. Disponível em: $<$ https://bv.fapesp.br/pt/bolsas/186964>. Acesso em: 03 jul. 2021.

${ }^{6}$ Com contribuição do segundo autor.

${ }^{7}$ Destacamos que este livro foi possível a partir de bolsa de pesquisa no exterior (BPE) - fomentada pela Fundação de Amparo à Pesquisa do Estado de São Paulo (FAPESP) - que nos possibilitou permanecer nos EUA por três meses. Disponível em: <https://bv.fapesp.br/pt/bolsas/186964>. Acesso em: 03 jul. 2021.
} 
de artigos disponíveis sobre a temática - utilizei documentos (normativos, informativos e curriculares) da instituição investigada ${ }^{8}$ disponível em seu portal $^{9}$, bem como dados do portal da Fundação Carnegie ${ }^{10}$.

No entanto, reconhecemos possíveis limitações para construção deste trabalho devido ao nosso "olhar estrangeiro" para a realidade investigada - para tanto, buscamos um olhar a partir da perspectiva antropológica de alteridade. Todavia, compreendemos a importância dele como estudo exploratório e descritivo para quem desejar assumir a empreitada de investigar melhor a rede das Tribal Colleges estadunidense. Para tanto, buscaremos apreender alguns dos possíveis significados dados a tal rede de ensino às comunidades indígenas dos Estados Unidos da América (EUA). Cabe destacar, a partir de Laplantine (2003), que "o conhecimento (antropológico) da nossa cultura passa inevitavelmente pelo conhecimento das outras culturas; e devemos especialmente reconhecer que somos uma cultura possível entre tantas outras, mas não a única" (p. 13).

Destaco ainda que a intenção deste artigo não é subsidiar políticas públicas de educação superior para comunidades indígenas brasileiras (ou de outros países lusófonos), pois temos a convicção de que tais comunidades se caracterizam como povos e nações originárias que enfrentam desafios diferentes em realidades diversas. Mas sim, entender uma cultura a partir dela mesma com o intuito de contribuir com as seguintes urgências:

a) Urgência de preservação dos patrimônios culturais locais ameaçados (...); b) Urgência de análise das mutações culturais impostas pelo desenvolvimento extremamente rápido de todas as sociedades contemporâneas, que não são mais "sociedades tradicionais", e sim sociedades que estão passando por um desenvolvimento tecnológico absolutamente inédito, por mutações de suas relações sociais, por movimentos de migração Interna, e por um processo de urbanização acelerado (...) (LAPLANTINE, 2003, p. 20).

Nesse sentido, destacamos que, para construção deste texto, nos utilizamos do conceito de relativismo preconizado pela Antropologia Social, o qual diz respeito a recuperar e colocar as experiências humanas lado a lado para um diálogo fecundo, tomando como ponto de partida a posição e o ponto de vista do "Outro", estudando-o pelos diversos meios possíveis - considerando seus dados históricos, econômicos e políticos no processo de reflexão (DAMATTA, 2010). Ou seja, possibilidade de "(...)

\footnotetext{
${ }^{8}$ Destacamos que para escrita deste manuscrito nos utilizamos apenas de documentos públicos da instituição estudada, pois devido a normas éticas estadunidenses não tivemos permissão para produção de dados diretamente ou indiretamente com a instituição por envolver comunidades indígenas. Apesar de termos ido à instituição e conversado com profissionais - enquanto futuros usuários -, não utilizaremos tais informações específicas, apesar de terem sido fundamentais para compreendermos a dinâmica curricular dos cursos da instituição.

${ }^{9}$ Disponível em: < https://www.sagchip.edu/>. Acesso em: 03 jul. 2021.

${ }^{10}$ Disponível em: $<$ https://carnegieclassifications.iu.edu>. Acesso em: 03 jul. 2021.
} 
Espaço Ameríndio

vivenciar sem intermediários a diversidade humana na sua essência e nos seus dilemas, problemas e paradoxos. Em tudo, enfim, que permitirá relavizar-se e assim ter a esperança de transformar-se num homem verdadeiramente humano" (DAMATTA, 2010, p. 173).

\section{As two-year colleges e o sistema educacional estadunidense}

O sistema educacional estadunidense é bastante diversificado considerando a autonomia constitucional dada às unidades federativas (estados) daquele país, conforme apontei em trabalho anterior:

Nos EUA, o governo é descentralizado e o controle de muitas funções públicas, como o ensino escolar, fica a cargo, essencialmente, dos estados e das comunidades locais. O governo federal adentra no campo da educação quando os estados ou as localidades não defendem um interesse que seja nacional, ou quando é exigida uma liderança nacional para se ocupar de um problema comum a toda a nação. Em regra, a função federal na educação baseia-se em dispositivo constitucional (United States of America, 1787a, art. $1^{0}$ ), que atribui ao Congresso dos EUA o poder de promover o bem-estar geral da nação. Na Constituição Federal não há nada específico em termos de educação, que deve estar subentendida no que se pode entender por bem-estar do cidadão, ficando a cargo das Constituições Estaduais versarem sobre questões de política educacional.

O Departamento de Educação dos EUA seria o equivalente ao Ministério da Educação no Brasil, porém, entre tantas diferenças, ele não se ocupa, diretamente, por exemplo, de questões de organização e desenvolvimento curricular, seja na proposição de diretrizes ou na regulação de meio e métodos de implantação diretamente das políticas educacionais. Com o aval do Congresso dos EUA, o Departamento de Educação se limita a regulamentar e aplicar direitos constitucionais federais. Ele exerce autoridade indireta por meio de financiamento federal de programas nacionais e do grants (subvenções), embora não haja nenhuma obrigação para qualquer estado aceitar esses fundos. O governo federal também pode propor, mas não pode impor metas, objetivos e normas nacionais, que geralmente estão além da sua jurisdição. Os estados e os distritos escolares locais estadunidenses são responsáveis pela manutenção do controle dos programas e métodos de ensino, estando o governo dos EUA proibido, por lei federal, de interferir nessas áreas. A autoridade para regular a educação centra-se, 
constitucionalmente, nos estados. (PERALTA; DIAS; GONÇALVES, 2018, p. 970-971)

Em geral' ${ }^{11}$, nos Estados Unidos o sistema educacional é organizado conforme figura 1 .

Figura 1: Sistema Educacional dos EUA

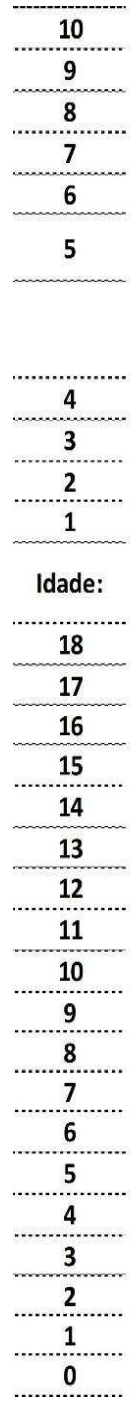

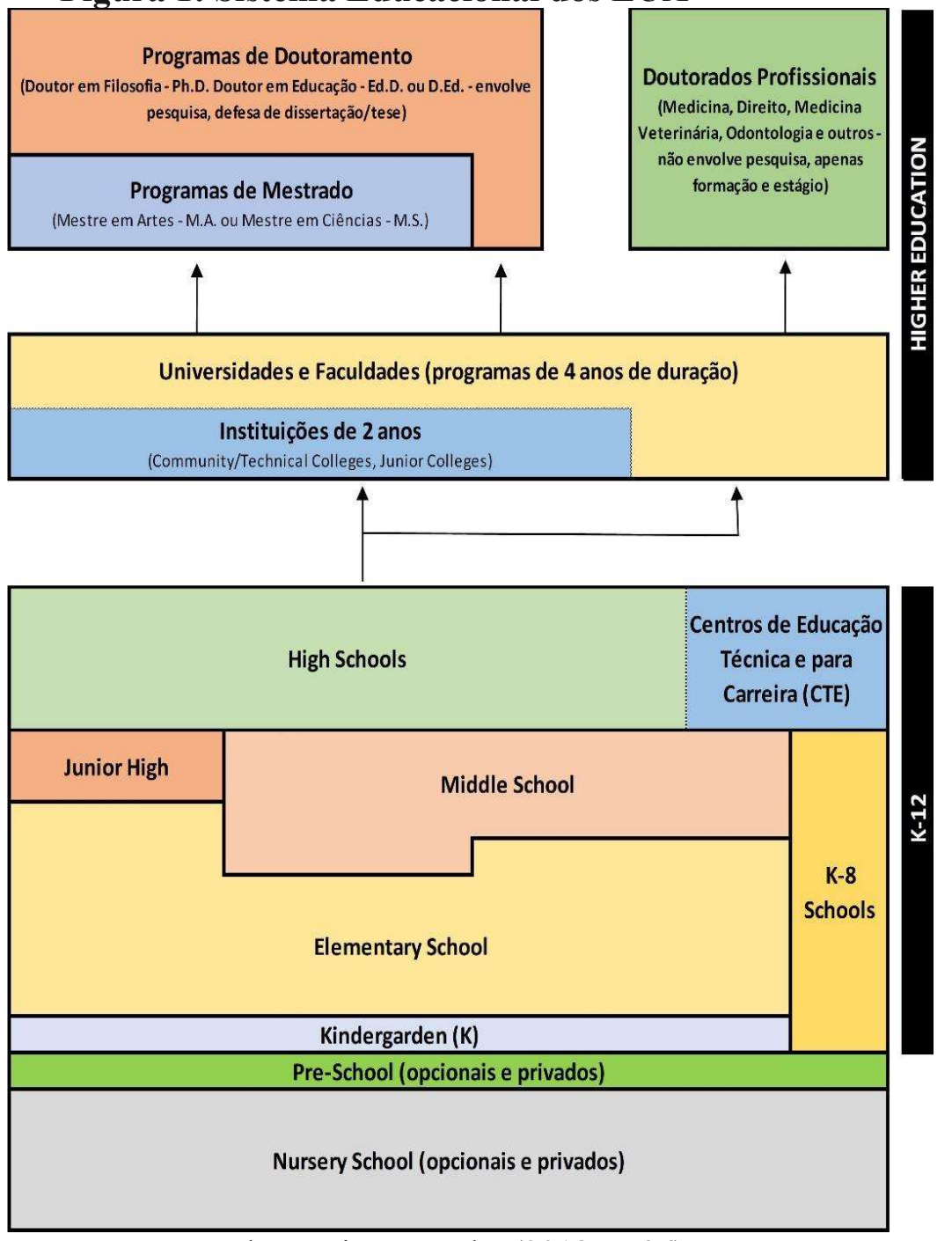

Fonte: Gonçalves, Dias e Peralta (2018, p. 36)

O que no Brasil compreendemos como Educação Infantil, nos Estados Unidos ocorre em estabelecimentos de ensino privados chamados de Nursery School (em português: Escola Infantil) e Pre-School (em português: Pré-Escola). Em geral, a Educação Básica daquele país, chamada de $\mathrm{K}-12$, é realizada em instituições diversas (públicas e privadas) e compreende 12 anos de escolarização obrigatória anterior à Educação Superior, organizada desde o kindergarden (em português: Jardim de Infância, K-1 - alfabetização) ao High School (em português: colegial / escola secundária - com duração de quatro anos K-9 ao K-12) ${ }^{12}$.

\footnotetext{
${ }^{11}$ Atentamo-nos ao estado de Michigan.

12 Equivalente ao Ensino Médio brasileiro.
} 
Os oito primeiros anos da escolarização básica ${ }^{13}$ são estruturados da seguinte forma: "do 1. ao 6.' ano, os alunos frequentam a chamada elementary school, equivalente aos anos iniciais do Ensino Fundamental brasileiro; do 7.' ao 8. ano, frequentam a middle school ou junior high school, equivalendo aos anos finais do Ensino Fundamental brasileiro" (GONÇALVES; DIAS; PERALTA, 2018, p. 38).

A formação na High School (K-9 a K-12) poderá ser realizada de forma integrada a uma formação para carreira profissional (Career and Technical Education - CTE). Ressalto explicação dada em trabalho anterior,

O termo utilizado internacionalmente na literatura de língua inglesa para a educação vocacional é Vocational Education and Training (VET, em português: Educação Vocacional e Treinamento). No Brasil, a modalidade VET é denominada Educação Profissional e Tecnológica (EPT), enquanto nos Estados Unidos da América o termo cunhado para designar o sistema, desde 1998, é Career and Technical Education (CTE). Reconhecemos que tais palavras têm significados e peculiaridades, e assumem diversas conotações nos diferentes sistemas de ensino, todavia não problematizamos tais significados neste trabalho. (GONÇALVES; DIAS; PERALTA, 2018, p. 33)

Gordon (2014) esclarece que a lei estadunidense que rege a CTE nos EUA é a Perkins IV (The Carl D. Perkins CTE Improvement Act of 2006, lei pública 109-270, de 2016). Perkins IV é a mais recente de uma série de reautorizações do Carl D. Perkins Vocational Education Act of 1984 (lei pública 98-524, de 2016) - substituiu o Vocational Education Act de 1963 e suas ementas de 1968 e 1976 (GORDON, 2014).

Nesse sentido, desde o High School o estudante pode optar por uma formação em CTE, podendo tal rede se configurar até a Higher Education (em português: Educação Superior). Nesse nível de estudos póssecundários, os cursos se caracterizam como undergraduate e graduate.

Enquanto no Brasil o primeiro nível de educação pósensino médio corresponde à graduação, proporcionando títulos de bacharel ou licenciatura, com duração típica de quatro ou cinco anos (embora existam também os cursos de formação de tecnólogos e sequenciais de curta duração), nos EUA o primeiro nível é o de undergraduate, em cursos de dois ou quatro anos, preparando os alunos seja para os cursos superiores de graduação, em nível de mestrado, doutorado ou em profissões consideradas lá como com exigências especializadas como engenharia, medicina e direito, seja para atividades profissionais não acadêmicas, de tipo mais prático ou aplicado, ou vocacional. (PERALTA: DIAS: GONÇALVES,2018, p. 971)

\footnotetext{
${ }^{13}$ Equivalente ao Ensino Fundamental brasileiro.
} 
Assim, a formação pós-secundária pode ocorrer tanto no âmbito do CTE quanto em rede acadêmica - comumente nas universidades.

Conforme Ghisolfi (2004), na maior parte das vezes o sistema de educação superior estadunidense é tripartite, formado pelos Junior Colleges, Colleges e Universidades; trata-se de um sistema hierarquizado em que os "Two-Year Colleges" (em português: faculdades de dois anos ou Junior Colleges) se constituem o primeiro nível (ou a base) destas instituições pós-secundárias.

Ainda em Ghisolfi (2004), destaco que a educação superior dos Estados Unidos se constitui como um sistema diversificado, facetado e hierarquizado em que se registra o maior número de matrículas no ensino superior do mundo, sendo um sistema "bem-sucedido" de educação póssecundária de massas. Considerando a ecleticidade de tal sistema, opto ${ }^{14}$ por descrevê-lo a partir da Carnegie Classification of Institutions of Higher Education $^{15}$ (em português: Classificação Carnegie das Instituições de Educação Superior), especificamente a de $2018^{16}$, desenvolvida pela Fundação Carnegie que desde os anos 70 tem se preocupado em organizar relatórios da educação superior ${ }^{17}$ daquele país, sendo uma das principais ferramentas para reconhecer e descrever a diversidade institucional da educação superior estadunidense - conforme disposto no próprio portal da instituição.

Segue na tabela 1 a distruição em número das matrículas no sistema de educação superior estadunidense - ao longo do texto apresentarei esses diversos níveis e programas de ensino da educação pós-secundária estadunidense.

Tabela 1 - Instituições de Educação Pós-Secundária Estadunidense por Foco em Graus e Programas

\begin{tabular}{l|c|c|c|c}
\hline \multirow{2}{*}{} & \multicolumn{2}{|c|}{ Instituições } & \multicolumn{2}{c}{ Matrículas Outono } \\
\cline { 2 - 5 } & $\mathbf{2 0 1 7}$ \\
\hline Universidades de Doutorado & $\mathbf{N}$ & $\mathbf{N}$ & $\mathbf{\%}$ \\
\hline Universidades e Faculdades de Mestrado & 418 & $10 \%$ & 7.229 .265 & $36 \%$ \\
\hline Faculdades de Bacharelados & 685 & $16 \%$ & 3.955 .922 & $20 \%$ \\
\hline Faculdades de Bacharelados e Associate & 575 & $13 \%$ & 989.818 & $4 \%$ \\
\hline Faculdades de Associate (Two-Year Colleges) & 262 & $6 \%$ & 1.270 .740 & $6 \%$ \\
\hline Foco Especial: Two-Year & 1000 & $23 \%$ & 5.808 .423 & $29 \%$ \\
\hline Foco Especial: Four-Year & 432 & $10 \%$ & 183.775 & $1 \%$ \\
\hline Tribal Colleges & 918 & $21 \%$ & 700.424 & $3 \%$ \\
\hline TOTAL & 34 & $1 \%$ & 16.424 & $0,1 \%$ \\
\hline
\end{tabular}

Fonte: Indiana University (2018, p. 2) - tradução nossa

A tabela 1 revela um gigantesco sistema de educação superior, em que mais de $50 \%$ das matrículas estão concentradas em universidades e um número significativo está concentrado nas Two-Year Colleges (36\%).

\footnotetext{
14 Seguindo os passos de Ghisolfi (2004).

${ }^{15}$ Disponível em: < https://carnegieclassifications.iu.edu/>. Acesso em: 03 jul. 2021.

16 Disponível em: <https://carnegieclassifications.iu.edu/downloads/CCIHE2018-FactsFigures.pdf $>$. Acesso em: 03 jul. 2021.

${ }^{17}$ Relatório publicado originalmente em 1973 e, posteriormente, atualizado em 1976, 1987, 1994, 2000, 2005, 2010, 2015 e 2018.
} 
Destaco que, apesar de percentualmente representar apenas 0,1\% das matrículas, as Tribal Colleges representam 16.424 matrículas no sistema de educação superior estadunidense.

Nos Estados Unidos, os programas de graduação (undergraduate programs) são organizados em Two-Year Colleges e as instituições de quatro anos (Four-Year Colleges ou universidades) de acordo com o grau conferido. Essas instituições oferecem cursos acadêmicos, domínio das Arts \& Sciences (Artes e Ciências), ou profissionais ${ }^{18}$. Assim, as instituições de graduação (undergraduate) estadunidenses se caracterizam da seguinte forma: (i) faculdades que fornecem o grau de associate - Two-Year Colleges; (ii) faculdades que podem conceder os graus de associate ou de bacharelados; (iii) faculdades em que a maioria de seus cursos de graduação concedem o grau de bacharelado - FourYear Colleges.

Apesar dos termos Junior Colleges, Community Colleges ou TwoYear Colleges serem tratados como sinônimos por alguns autores, Ghisolfi (2004) alerta que administrativamente o termo Two-Year College é um termo generalizador, sendo comumente três tipos dessas instituições - voltadas para cursos CTE: (i) Junior Colleges - instituições mais antigas, majoritariamente privadas, que oferecem cursos superiores de dois anos - acadêmicos ou técnicos ${ }^{19}$; (ii) Technical Colleges instituições com cursos de dois anos, geralmente profissionalizantes e majoritariamente técnicos, que levam diretamente a uma ocupação ou emprego; (iii) Community Colleges - são instituições públicas que oferecem cursos de natureza acadêmica, técnicos e de educação continuada. Além de prestar outros serviços para a comunidade local, "os Community Colleges ampliam o acesso à modalidade de educação profissionalizante. A principal função do Community College é a chamada 'vocational education', e não a possibilidade de transferência para um fouryear college" (GHISOLFI, 2004, p. 87).

As Two-Year Colleges concedem o grau Associate ${ }^{20}$ promovendo formações para carreiras técnicas profissionais: (i) Associate of Arts (AA) - um diploma de associate em Artes dispõe de currículo mais amplos e generalista (ideia de formação nas artes liberais), possibilitando ao estudante um posterior ingresso numa carreira especializada em formação posterior (bacharelado); (ii) Associate of Science (AS) - um diploma em associate em Ciências também possibilita uma formação ampla, semelhante àquela oferecida pelo AA, todavia com foco mais específico em STEM (Ciência, Tecnologia, Engenharia e Matemática) para aqueles que têm interesse em aprofundamentos nessa área em estudos posteriores (bacharelados); (iii) Associate of Applied Science (AAS) - um diploma em ciências aplicadas tem natureza vocacional, pois se caracteriza como uma formação altamente específica e voltada para uma

\footnotetext{
18 A Fundação Carnegie chama de Professional/Vocational/Technical Focus (em português: Foco profissional/vocacional/técnico).

${ }^{19}$ Os cursos técnicos oferecidos nos EUA são de natureza pós-secundária articulados com a educação superior (e, por vezes, à educação secundária - technical colleges), diferentemente do Brasil em que os cursos técnicos são de nível médio e os tecnólogos de nível superior.

${ }^{20}$ Em português: Associado - porém opto por não traduzir tal termo no corpo do trabalho.
} 
profissão técnica - pressuponho que esses cursos se aproximam dos de tecnólogos oferecidos no Brasil. Nem sempre os egressos desses cursos (Associate) conseguem se transferir para uma instituição de quatro anos.

Essas formações em AA e AS são rotuladas pela Fundação Carnegie como aquelas que dispõem "foco na transferência", pois são programas de formação em que o objetivo central é a transferência dos egressos para os bacharelados de uma instituição de quatro anos como continuum de sua formação. Grande parte das Two-Year Colleges são as Community Colleges. Cabe destacar que elas, além do diploma de Associate, oferecem outros tipos de formações que conferem diplomas ou certificados de educação continuada que nem sempre são contabilizados como créditos acadêmicos.

A Fundação Carnegie utiliza três categorias ${ }^{21}$ para classificar os cursos dessas Two-Year Colleges ${ }^{22}$ (conforme tabela 2): (i) High Transfer - instituições concederam graus de Associate, mas nenhum de bacharelado, com menos de $30 \%$ de diplomas e certificados em programas profissionais ${ }^{23}$; (ii) Mixed Transfer / Career Tech - instituições concederam graus de Associate, mas nenhum de bacharelado, com 30 a 49\% dos diplomas e certificados em programas profissionais; (iii) High Career Tech - instituições concederam graus de Associate, mas nenhum de bacharelado, com mais de $50 \%$ dos diplomas e certificados em programas profissionais.

Para as instituições de quatro anos (Four-Year Colleges ou universidades), empreguei as cinco categorias utilizadas pela Fundação Carnegie $^{24}$ para apresentar quantitivamente estas instituições (criadas a partir de dados de diplomação nos cursos) ${ }^{25}$ : (i) Arts \& Sciences Focus pelo menos $80 \%$ dos cursos de bacharelado foram em áreas acadêmicas ${ }^{26}$ e nenhum diploma de pós-graduação ${ }^{27}$ foi concedido em áreas correspondentes aos cursos de graduação; (ii) Arts \& Sciences Plus Professions - maior parte (60-79\%) dos cursos de bacharelado foram nas áreas acadêmicas e nenhum diploma de pós-graduação foi concedido em áreas correspondentes aos cursos de graduação; (iii) Professions Plus Arts \& Sciences - maior parte (60\% a $79 \%)$ dos cursos de bacharelado estavam em áreas profissionais (como negócios, educação, engenharia, saúde e assistência social) e nenhum diploma de pós-graduação foi concedido em áreas correspondentes aos cursos de graduação; (iv) Balances Arts \& Sciences / Professions - equilíbrio entre as áreas acadêmicas e profissionais (41 a 59\% em cada) e nenhum diploma de pós-graduação foi concedido em áreas correspondentes aos cursos de graduação; (v) Professions Focus - pelo menos $80 \%$ dos cursos de bacharelado foram em

\footnotetext{
${ }^{21}$ Explicaremos as categorias (tanto das Two-Year Colleges quanto das instituições de quatro anos), porém optamos por não mantê-las traduzidas no corpo do trabalho.

${ }^{22}$ Disponível em: $<$ https://carnegieclassifications.iu.edu/classification_descriptions/ugrad_program.php $>$. Acesso em: 03 jul. 2021.

${ }^{23}$ Neste caso compreendido como CTE.

${ }^{24}$ Disponível em: < https://carnegieclassifications.iu.edu/classification_descriptions/ugrad_program.php>. Acesso em: 03 jul. 2021.

${ }^{25}$ Apenas instituições focadas na graduação e não na pós-graduação.

${ }^{26}$ Chamada no relatório da Fundação Carnegie de "Artes \& Ciências".

${ }^{27}$ Mestrados e doutorados.
} 
Espaço Ameríndio

áreas profissionais (como negócios, educação, engenharia, saúde e assistência social) e nenhum diploma de pós-graduação foi concedido em áreas correspondentes aos cursos de graduação.

Apresentamos na tabela 2 , os dados do relatório da Fundação Carnegie.

Tabela 2 - Foco dos Programas de Graduação

\begin{tabular}{|c|c|c|c|c|c|}
\hline \multirow{2}{*}{\multicolumn{2}{|c|}{ Undergraduate Programs / Programas de Graduação }} & \multicolumn{2}{|c|}{ Instituições } & \multicolumn{2}{|c|}{$\begin{array}{l}\text { Matrículas - } \\
\text { outono } 2017\end{array}$} \\
\hline & & № & $\%$ & № & $\%$ \\
\hline $\begin{array}{c}\text { Faculdades Associadas } \\
\text { (dois anos) }\end{array}$ & $\begin{array}{l}\text { High Transfer } \\
\text { Mixed Transfer/Career Tech } \\
\text { High Career Tech }\end{array}$ & $\begin{array}{l}342 \\
311 \\
347 \\
\end{array}$ & $\begin{array}{l}34 \% \\
31 \% \\
35 \% \\
\end{array}$ & $\begin{array}{c}2.935 .267 \\
1.967 .804 \\
905.352 \\
\end{array}$ & $\begin{array}{l}51 \% \\
34 \% \\
16 \% \\
\end{array}$ \\
\hline \multicolumn{2}{|l|}{ Subtotal } & 1000 & - & 5.808 .423 & - \\
\hline $\begin{array}{c}\text { Faculdades } e \\
\text { Universidades (quatro } \\
\text { anos) }\end{array}$ & $\begin{array}{l}\text { Arts \& Sciences Focus } \\
\text { Arts \& Sciences Plus Professions } \\
\text { Balances Arts \& Sciences / Professions } \\
\text { Professions Plus Arts \& Sciences } \\
\text { Professions Focus }\end{array}$ & $\begin{array}{l}162 \\
185 \\
495 \\
664 \\
656 \\
\end{array}$ & $\begin{array}{c}7 \% \\
9 \% \\
23 \% \\
31 \% \\
30 \% \\
\end{array}$ & $\begin{array}{c}454.980 \\
1.062 .535 \\
4.744 .249 \\
4.728 .528 \\
1.450 .962 \\
\end{array}$ & $\begin{array}{c}4 \% \\
9 \% \\
38 \% \\
38 \% \\
12 \% \\
\end{array}$ \\
\hline \multicolumn{2}{|l|}{ Subtotal } & 2.162 & - & 12.441 .254 & - \\
\hline \multicolumn{2}{|l|}{ TOTAL } & \multicolumn{2}{|c|}{3162} & \multicolumn{2}{|c|}{18.249 .677} \\
\hline
\end{tabular}

Fonte: Relatório de Classificação Carnegie das Instituições de Educação Superior

(INDIANA UNIVERSITY, 2018) - traduzido e adaptado pelos autores.

Cabe destacar que os custos dos créditos em uma Two-Year College é bem menor em relação às instituições de quatro anos, fazendo com que alguns estudantes optem por realizar seus dois primeiros anos de formação nas Two-Year Colleges. Tomemos como exemplo o valor do crédito em três instituições localizadas na cidade de Mount Pleasant (Michigan): US\$ 417 (nível inferior - menos de 56 créditos) na Central Michigan University (CMU) ${ }^{28}$; US\$ 129 (residentes no distrito) e US\$ 217 (residentes fora do distrito) no Mid Michigan College ${ }^{29}$ (Community College $^{30}$ ); US\$ 60 no Saginaw Chippewa Tribal College ${ }^{31}$. Tais dados demonstram uma economia considerável aos estudantes que almejam estudar em uma universidade estadunidense, chegando esses dados a serem utilizados como propaganda para atrair novos alunos para as TwoYear Colleges (vide figura 2). 03 jul. 2021.

${ }^{29}$ Disponível em: <https://www.midmich.edu/admissions/paying-for-college> . Acesso em: 19 fev. 2020.

${ }^{30}$ Os Community Colleges têm programas de incentivo financeiro para estadantes do distrito em que eles estão localizados.

${ }^{31}$ Disponivel em: <https://www.sagchip.edu/why-sctc>. Acesso em: 03 jul. 2021. 
Espaço Ameríndio

Figura 2 - Comparação Mid Michigan College com algumas Universidades

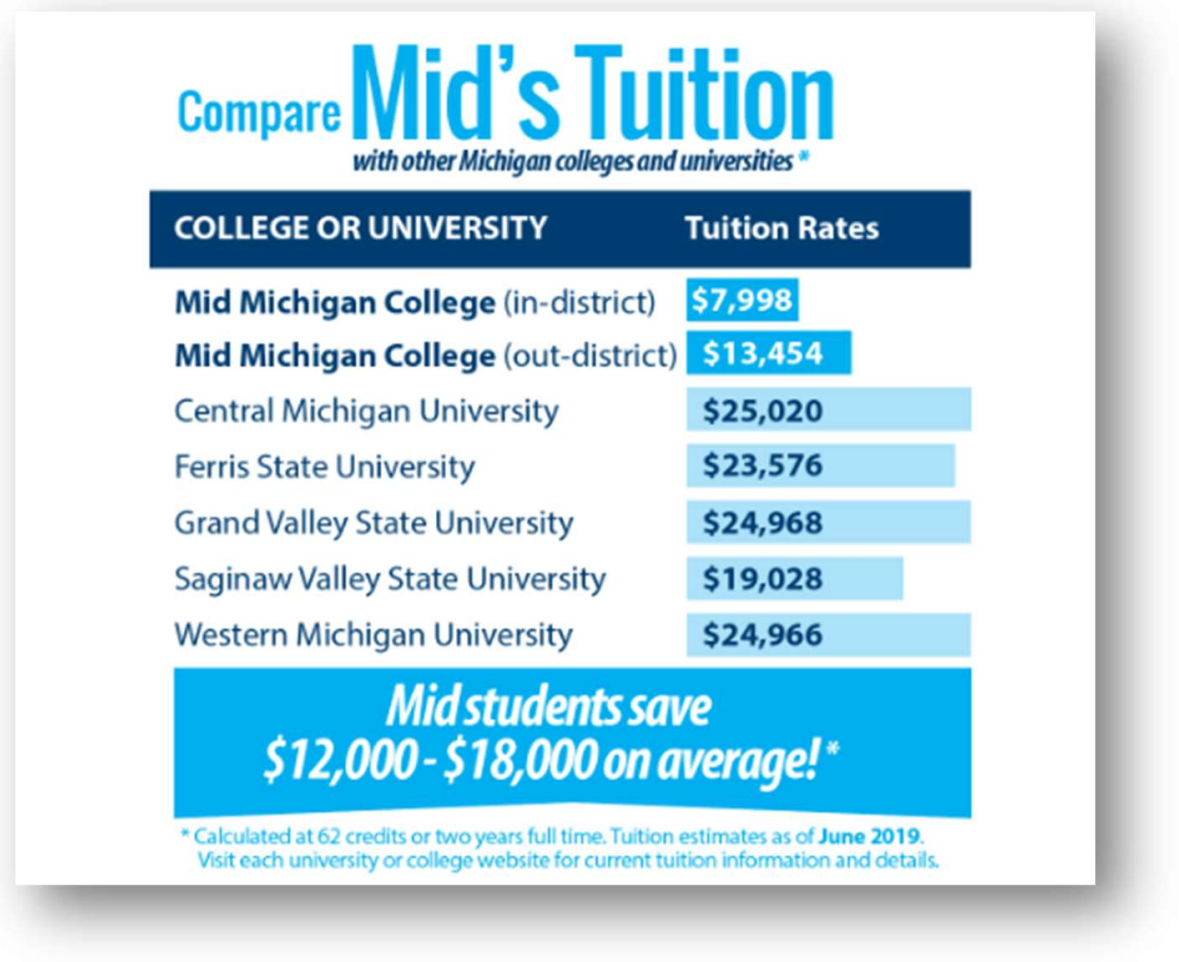

Fonte: site da instituição $0^{32}$

A figura 2 mostra a diferença financeira aos que desejam cursar os dois primeiros anos de sua formação no Mid Michigan College em relação às anuidades pagas às universidades da região. Conforme já apontamos, as Two-Year Colleges, em especial as community colleges, organizam os seus programas de formação vocacionais/ ocupacionais (ciências aplicadas destinado a um profissionalização - AAS) e não vocacionais / não ocupacionais (programas acadêmicos ${ }^{33}$ - AA ou AS). Tomemos, como exemplo, os programas do Mid Michigan College (quadro 1):

\section{Quadro 1 - Cursos Oferecidos pelo Mid Michigan College $e^{34}$}

\footnotetext{
${ }^{32}$ Disponível em: <https://www.midmich.edu/admissions/paying-for-college>. Acesso em: 19 fev. 2020.

${ }^{33}$ Arts \& Sciences

${ }^{34}$ Opto por não apresentar na tabela outros programas que não oferecem o grau de Associate, mas que são de formação profissional oferecidos pela instituição: Designer de Web (certificado), Assistente Administrativo (certificado), Tecnologia de Tomografia Computadorizada (credencial avançada), Técnico Farmacêutico (certificado), Educação Infantil (certificado), Manufatura Integrada Avançada - Automação / Robótica (credencial de treinamento), Fabricação Integrada Avançada - Máquinas-Ferramenta (credencial de treinamento), Manufatura Integrada Avançada - Pré-Aprendiz (credencial de treinamento), Serviço automotivo e diesel (credencial de treinamento), Desenho Assistido por Computador (cerfificado), Soldagem (certificado), Instalações, Aquecimento, Especialista em eletricidade - HRA (credencial de treinamento), Especialista em Refrigeração / Ar Condicionado - HRA (credencial de treinamento), Credencial avançado geotérmica - HRA (credencial de treinamento). Outros programas ou treinamentos de curto prazo também são oferecidos na instituição: Auxiliar de Enfermagem (CNA) - preparação para certificação, Carteira de Habilitação Comercial (CDL-A) - programa de treinamento, Agente Comunitário de Saúde - programa de treinamento, Piloto de Drone - treinamento e preparação para certificação, Aprendiz Elétrico, Programa de Manufatura / Plásticos, Flebotomia - preparação para certificação, Soldagem - programa de treinamento.
} 


\begin{tabular}{|c|c|c|}
\hline ÁREA & PROGRAMA & GRAU \\
\hline \multirow{6}{*}{$\begin{array}{c}\text { Artes e } \\
\text { Comunicações }\end{array}$} & Design gráfico & AAS \\
\hline & História e Ciência Política (foco na transferência) & $\mathrm{AA}^{*}$ \\
\hline & Transferência de Estudos Liberais (foco na transferência) & AA \\
\hline & Transferência de psicologia (foco na transferência) & $\mathrm{AA}^{*}$ \\
\hline & Transferência de Sociologia (foco na transferência) & AA* \\
\hline & Transferência de Artes Visuais (foco na transferência) & AA \\
\hline \multirow{10}{*}{$\begin{array}{l}\text { Business }^{35} \text { e } \\
\text { Tecnologia }\end{array}$} & Contabilidade & AAS \\
\hline & Assistente Administrativo (profissional) & AAS* \\
\hline & Assistente Administrativo (escritório jurídico) & AAS* \\
\hline & Assistente Administrativo (consultório médico) & AAS* \\
\hline & Manufatura Integrada Avançada (Gerenciamento) & $\overline{\mathrm{AAS}}$ \\
\hline & Business & $\underline{\underline{\mathrm{AAS}^{*}}}$ \\
\hline & Estudos em Business (foco na transferência) & $\mathrm{AA}$ \\
\hline & $\begin{array}{l}\text { Estudos em Business (aprimorada) }(3+1 \text { para gerenciamento) } \\
\text { (foco na transferência) }\end{array}$ & $\overline{\mathrm{AA}}$ \\
\hline & $\begin{array}{l}\text { Sistemas de Informação Computacional (Infraestrutura de TI e segurança } \\
\text { cibernética) }\end{array}$ & $\underline{\mathrm{AAS}}$ \\
\hline & Sistemas de Informação Computacional (Desenvolvimento de Software) & AAS \\
\hline \multirow{8}{*}{$\begin{array}{l}\text { Ciências da } \\
\text { Saúde }\end{array}$} & Ciências da Saúde (foco na transferência) & $\overline{\mathrm{AS}}$ \\
\hline & Ressonância Magnética (RM) & AAS \\
\hline & Assistente médico & AAS \\
\hline & Tecnólogo em Neurodiagnóstico (EEG) & AAS \\
\hline & Enfermagem & $\mathrm{ADN}^{* *}$ \\
\hline & Assistente de Fisioterapeuta & AAS \\
\hline & Saúde Pública & AAS \\
\hline & Radiografia (raio X) & AAS \\
\hline \multirow{7}{*}{$\begin{array}{l}\text { Serviços } \\
\text { Humanos }\end{array}$} & Justiça Criminal (Polícia) (foco na transferência) & AA \\
\hline & Justiça Criminal (correções estaduais) & AAS \\
\hline & Justiça Criminal (Detenção Local) & AAS \\
\hline & Justiça Criminal (Pré-Serviço) & AAS \\
\hline & Educação Infantil & AAS \\
\hline & Educação (ensino fundamental) (foco na transferência) & $\mathrm{AA}$ \\
\hline & Educação (ensino médio) (foco na transferência) & AA \\
\hline \multirow{5}{*}{$\begin{array}{l}\text { Matemática e } \\
\text { Ciências }\end{array}$} & Biologia (foco na transferência) & AS \\
\hline & $\begin{array}{l}\text { Biologia (específico para ingresso na Central Michigan University - } \\
\text { CMU) (foco na transferência) }\end{array}$ & AS \\
\hline & Química (foco na transferência) & AS \\
\hline & Matemática (foco na transferência) & AS \\
\hline & Física (foco na transferência) & AS \\
\hline \multirow{8}{*}{ Comércio } & Manufatura Integrada Avançada (Automação / Robótica) & AAS \\
\hline & Manufatura Integrada Avançada (Gerenciamento) & AAS \\
\hline & Fabricação Integrada Avançada (Máquinas-Ferramenta) & AAS \\
\hline & Fabricação Integrada Avançada (Plásticos) & AAS \\
\hline & Fabricação Integrada Avançada (Soldagem) & AAS \\
\hline & Serviço automotivo e diesel & AAS \\
\hline & Desenho e Desenho Assistido por Computador (CADD) & AAS \\
\hline & (HRA) Instalações, Aquecimento, Refrigeração e Ar Condicionado & AAS \\
\hline
\end{tabular}

* Oferecido na modalidade Educação à Distância (EaD) $\quad$ ** Associate Degree in Nursing (Associate em Enfermagem) ${ }^{36}$

\footnotetext{
${ }^{35}$ Em português: negócios - opto por manter o termo em inglês por se conhecido de tal forma no setor empresarial.

${ }^{36}$ É recomendada a conclusão do curso em três anos, garantindo o exercício da enfermagem no Estado de Michigan, pois é acreditada na National League for Nursing Commission for Nursing Education Accreditation (NLN-CNEA, em português: Liga Nacional de Enfermagem da Comissão de Acreditação de
} 
Considerando apenas os cursos que concedem o grau de Associate (vide gráfico - figura 3), observamos que a Mid Michigan College oferece $62 \%$ dos seus programas de formação no âmbito da CTE (AAS e ADN) e $38 \%$ cursos de natureza acadêmica (AA e AS) com foco na transferência. Apesar de a Fundação Carnegie constituir suas categorias a partir dos diplomas emitidos pelas instituições, acredito que a Mid Michigan College se caracteriza como High Career Tech.

Figura 3: - Grau de Associate oferecido pela Mid Michigan College

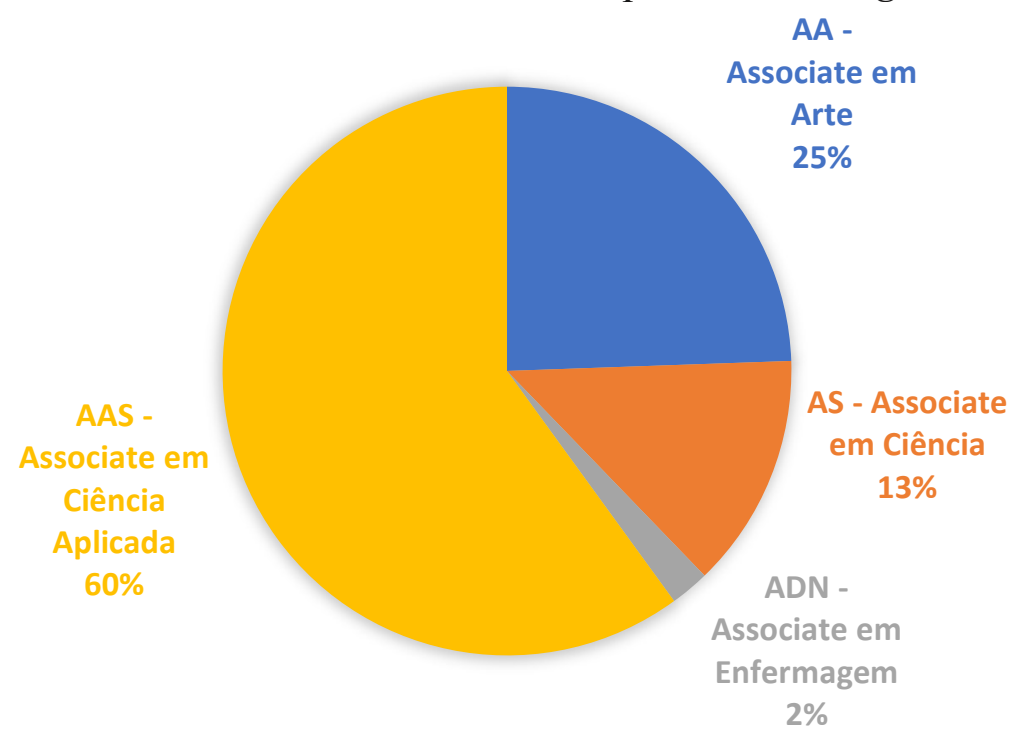

Fonte: Listagem dos Programas da Mid Michigan College ${ }^{38}$

Destaco que o CTE dispõe de cursos profissionalizantes voltados para o (mercado de) trabalho a partir de uma ocupação/carreira profissionais, sendo desde programas de curta duração (inclusive preparatórios para exames obrigatórios para licenças específicas) até a concessão do grau Associate em Ciências Aplicadas (AAS) - os programas de formação em AAS recebem nomenclaturas diversas exemplificadas no quadro 1. No Brasil, o AAS se assemelha aos cursos de tecnólogos oferecidos por faculdades ou universidades, apesar de não serem equivalentes - saliento que os cursos técnicos brasileiros são de nível médio e não pós-secundários de nível superior.

Ghisolfi (2004) destaca que as Two-Year Colleges "oferecem cursos (especialmente da área técnica) em cooperação com indústrias locais, agências de serviços públicos (como hospitais, clínicas de enfermagem, etc.) e empresas regionais, o que viabiliza mais rápido acesso a um emprego ou ocupação" (p. 70). A autora esclarece que o financiamento

Educação em Enfermagem), devendo o estudante realizar exame para obtenção de licença para o exercício da profissão.

${ }^{37}$ Disponível em: $<$ https://www.midmich.edu/academics/programs-of-study>. Acesso em: 21 fev. 2020.

${ }^{38}$ Disponível em: $<$ https://www.midmich.edu/academics/programs-of-study>. Acesso em: 21 fev. 2020. 
dos community colleges é divido da seguinte forma: $42 \%$ são de fundo do estado, $23 \%$ de mensalidades e taxas, $18 \%$ de fundos locais (prefeituras, empresas etc), $5 \%$ de fundos federais e $10 \%$ de outras fundos.

Conforme apontamos anteriormente, uma característica importante das Two-Year Colleges daquele país é que tais instituições promovem, além da CTE, uma formação de natureza acadêmica (AA e AS) visando a transferência dos estudantes para complementar seus estudos em instituições de quatro anos nos cursos de bacharelado. Ou seja, parte considerável dos seus estudantes procuram tais instituições pelos seus baixos custos de mensalidades ou porque não obtiveram na high school coeficiente necessário para ingresso em uma universidade. Todavia, Ghisolfi (2004) afirma que o percentual nacional de transferências aceitas não ultrapassam $25 \%$.

A autora afirma que, dada a forma de organização federativa dos EUA, cada estado dispõe de um sistema educacional com características, ofertas e exigências peculiares. Assim, torna-se difícil que um aluno de uma Community College consiga se transferir para uma institução de quatro anos de outro estado pelas diferenças curriculares - embora existam seis regiões administrativas que procuram pradronizar os currículos das instituções do país - e pelo diferencial de preço que um aluno paga por não ser residente no estado, considerando os estímulos dados aos residentes, conforme o exemplo apresentado na figura 2.

Destacamos que tal natureza não é observada na realidade brasileira ${ }^{39}$; como exemplo temos as Faculdades de Tecnologias (FATEC), instituições paulistas que pertecem ao Centro Paula Souza ${ }^{40}$ que dispõem exclusivamente de cursos de graduação para formação de tecnológos nas diversas áreas profissionais (em geral de dois a três anos de duração semelhante ao modelo estadunidense Two-Year Colleges). Todavia, estes cursos não são pagos pelos estudantes, bem como garantem o acesso aos cursos de pós-graduação; diferentemente dos Estados Unidos, onde esses cursos são pagos pelos estudantes (apesar haver diversos programas públicos e privados de incentivos) e, para ingresso na pósgraduação, os egressos dos Associate necessitam complementar sua formação em cursos bacharelados.

Ghisolfi (2004) esclarece que, para o ingresso nas Two-Year Colleges estadunidenses, os estudantes não precisam participar de processo seletivo (com raras exceções) e nem ter concluído o ensino médio - bastando ter a idade mínima de 17 anos. Diferentemente do

\footnotetext{
${ }^{39}$ Conforme já apontado anteriormente, o grau de Associate estadunidense não é equivalente ao grau de tecnólogo no Brasil, mas entendo que possuem similaridades por disporem de uma formação de nível superior no âmbito da Vocational Education and Training (VET, em português: Educação Vocacional e Treinamento).

${ }^{40}$ Conforme dispoto no portal do Centro Paula Souza: "O Centro Paula Souza (CPS) é uma autarquia do Governo do estado de São Paulo, vinculada à Secretaria de Desenvolvimento Econômico. Presente em 322 municípios, a instituição administra 223 Escolas Técnicas (Etecs) e 73 Faculdades de Tecnologia (Fatecs) estaduais, com mais de 294 mil alunos em cursos técnicos de nível médio e superiores tecnológicos". Disponivel em: <https://www.cps.sp.gov.br/sobre-o-centro-paula-souza/>. Acesso em: 07 jul. 2021.
} 
Brasil que os alunos necessitam de participar de um processo seletivo em geral, o vestibular ${ }^{41}$ - para ingresso nos cursos tecnólogos.

A autora destaca algumas particularidades destas instituições: (i) adequada para trabalhadores ou jovens que necessitam ingressar mais cedo no mercado de trabalho; (ii) atendem pessoas de baixo poder aquisivo ou de grupos socialmente excluídos; (iii) mulheres representam de $57 \%$ a $63 \%$ das matrículas; (iv) pessoas mais velhas buscam nestas instituições formação continuada; ( $v$ ) além dos cursos diurnos, oferecem elas cursos noturnos; (vi) dispõem de creches para estudantes que tenham filhos.

Os two-year colleges surgiram cerca de quarenta anos após a implementação daquela lei - e expandiram-se quase cem anos mais tarde, no período pós-Segunda Guerra Munidal e nos anos 1960, com os movimentos sociais que tomaram conta da sociedade estadunidense. Ou seja: os two-year colleges surgem quando já existe uma elite nacional formada, que se depara com uma enorme massa de imigrantes e com milhares de pessoas socialmente excluídas que damandavam por diversas formas de inclusão social e cidadania. Assim, as elites se viram forçadas a ceder e incluir socialmente pelo menos uma parcela dessa população. Mas, é claro, ceder e incluir de forma controlada. (GHISOLFI, 2004, p. 88)

\section{Concordamos com Ghisolfi (2004) quando ela afirma}

Ao mesmo tempo em que a função principal dos twoyear colleges tem sido a de assegurar aos que são formalmente excluídos uma oportunidade de adquirir formação superior, estas instituições são encaradas como IES de "segunda categoria", profissionalizante, destinada a darem cursos profissionalizantes a pessoas que jamais ocuparão cargos privilegiados. A IES são de "segunda classe" para "cidadãos de segunda". (GHISOLFI, 2004, p. 78)

Assim, as Two-Year Colleges democratizam a formação superior das classes populares daquele país. Todavia, colaboram com a promoção de uma elite intelectual, excluindo parte dessa classe dos estudos em universidades - dados os altos valores das anuidades ou a carência de cursos ajustados à necessidade de trabalhadores -, bem como restringindo o acesso dessas classes à formação pós-graduada e, consequentemente, de acesso a algumas profissões oferecidas somente neste nível (como a Medicina, Direito, Engenharia etc) e/ou carreiras acadêmicas.

\footnotetext{
${ }^{41}$ Existem outras formas de ingresso nos cursos superiores no Brasil: sistemas de avaliação seriada aos alunos do Ensino Médio, aqueles que já são portadores de diploma de nível superior, Sistema de Seleção Unificada (SISU) organizado pelo Ministério da Educação (MEC) e utiliza as notas do Exame Nacional de Ensino Médio (ENEM).
} 
As instituições de quatro anos (Four-Year Colleges ou Universidades) dispõem de cursos de bacharelado ${ }^{42}$. Conforme já apresentamos anteriormente na tabela 2, estes cursos podem oferecer os seguintes programas: Arts \& Sciences Focus, Arts \& Sciences Plus Professions, Balances Arts \& Sciences / Professions, Professions Plus Arts $\&$ Sciences e Professions Focus.

Para melhor compreender o processo de formação de bacharéis nos Estados Unidos ${ }^{43}$, tomamos como exemplo a formação da Central Michigan University (CMU) - universidade pública localizada em Mount Pleasant (Michigan).

A CMU está organizada pelas seguintes faculdades (colleges): College of the Arts and Media (Faculdade de Artes e Mídia); College of Business Administration (Faculdade de Administração de Empresas); College of Education and Human Services (Faculdade de Educação e Serviços Humanos); The Herbert H. and Grace A. Dow College of Health Professions (Faculdade de Saúde Herbert H. e Grace A. Dow); College of Liberal Arts and Social Sciences (Faculdade de Artes Liberais e Ciências Sociais); College of Medicine (Faculdade de Medicina); College of Science and Engineering (Faculdade de Ciências e Engenharia); College of Graduate Studies (Faculdade de Estudos de Pós-Graduação) ${ }^{44}$. Além dessas faculdades, existe o Global Campus em que oferece alguns programas de formação disponíveis na modalidade Educação à Distância (EaD).

Por meio dessa estrutura, a CMU dispõe dos seguintes graus: Bacharel em Arte Aplicada; Bacharel em Artes; Bacharel em Belas-Artes; Bacharel em Estudos Individualizados; Bacharel em Música; Bacharel em Educação Musical; Bacharel em Ciências; Bacharel em Ciências com opção em Desenvolvimento Comuntário; Bacharel em Ciências em Treinamento Atlético; Bacharel em Ciências em Adminstração de Empresas; Bacharel em Ciências em Engenharia de Computação; Bacharel em Ciências em Educação; Bacharel em Ciências em Engenharia da Tecnologia; Bacharel em Ciências em Engenharia Mecânica; Bacharel em Ciências em Engenharia Elétrica.

No contexto destes supramencionados graus ${ }^{45}$, os graduandos podem construir sua trajetória formativa a partir de aproximadamente 200 programas acadêmicos. Ou seja, com o mesmo grau de bacharelado os graduandos podem dispor de trajetórias formativas diferentes de acordo com o programa acadêmico escolhido. Para tanto, cada acadêmico dispõe de um professor orientador/tutor para auxiliá-los nas suas escolhas curriculares.

\footnotetext{
${ }^{42}$ Em inglês: baccalaureate - optei por usar o termo bacharelado (em português) por se o mesmo usado no Brasil para se referir a um tipo de curso de graduação.

${ }^{43}$ Modelo utilizado em grande parte das universidades estadunidenses.

${ }^{44}$ Diretamente responsável pelos programas de pós-graduação da CMU.

${ }^{45}$ Além dos cursos de bacharelado, as universidades da CMU oferecem cursos de curta duração chamados de certificates undergraduates, geralmente oferecidos pelo Global Campus na modalidade EaD. Os certificados são planejados para aprimorar habilidades profissionais com duração de 12 a 18 créditos. Esses cursos são concebidos para atender às demandas do mercado de trabalho. Disponível em: $<$ https://go.cmich.edu/academics/Undergraduate/Find_Program/Pages/default.aspx $>$. Acesso em: 7 jul. 2021.
} 
Para melhor compreensão da graduação nos EUA - via CMU - os programas têm duração média de quatro anos e dispõem de um currículo altamente flexível com um núcleo geral e, dentre os diversos graus de bacharelado oferecidos pela instituição, os acadêmicos direcionam suas escolhas de trajetórias formativas a partir da composição de Major (em português, principal) ou Minor (em português, menor) previstos para conclusão dos programas de formação e que direcionam o conjunto mínimo de disciplinas obrigatórias a serem cursadas no programa escolhido.

O Major se caracteriza como uma área de estudo específica que garante a qualificação no título de bacharelado enquanto o Minor é uma área de estudo secundária - com quantidade menor de créditos do que o Major - e que garante a "inclusão" de qualificações ou habilidades no título de bacharelado. Em geral os acadêmicos devem escolher um Major e - podendo, além desse - escolher outro Major (chamado de Double Major) ou um ou mais Minor.

Alguns dos programas de formação têm natureza profissional (natureza ocupacional de inserção direta no mundo do trabalho) ou natureza mais generalista para inserção do egresso nos diversos programas de pós-graduação (Graduate Programs). Ou seja, profissões especializadas que se constituem na pós-graduação (como engenharia, medicina, direito, etc) ou em carreiras acadêmicas.

De acordo com a Fundação Carnegie ${ }^{46}$, o Carnegie Classification of Institutions of Higher Education classifica a pós-graduação estadunidense de acordo com a natureza dos programas, com um foco especial na combinação de programas de pós-graduação nos diversos campos de estudo considerando o nível de pós-graduação (mestrado e doutorado pesquisa ${ }^{47}$, prática profissional ou outros doutorados), número de campos representados pelos graus concedidos e "mistura ou concentração" de graus por amplo domínio disciplinar.

A Fundação Carnegie utiliza as categorias dispostas nos quadros 2 e 3 para classificar a pós-graduação nos Estados Unidos

Quadro 2 - Pós-Bacharelados

\begin{tabular}{|c|l|}
\hline $\begin{array}{c}\text { Educação } \\
\text { (Programa Único) }\end{array}$ & $\begin{array}{l}\text { concederam mestrado ou doutorado (prática profissional/outros) em educação } \\
\text { como seu único programa de pós-graduação. }\end{array}$ \\
\hline $\begin{array}{c}\text { Business } \\
\text { (Programa Único) }\end{array}$ & $\begin{array}{l}\text { concederam mestrado ou doutorado (prática profissional/outros) em business } \\
\text { como seu único programa de pós-graduação. }\end{array}$ \\
\hline $\begin{array}{c}\text { Outros } \\
\text { (Programa Único) }\end{array}$ & $\begin{array}{l}\text { concederam mestrado ou doutorado (prática profissional/outros) em um único } \\
\text { campo que não a educação ou business como seu único programa de pós- } \\
\text { graduação. }\end{array}$ \\
\hline $\begin{array}{c}\text { Comprehensive } \\
\text { Programs }\end{array}$ & $\begin{array}{l}\text { concederam pelo menos um mestrado ou doutorado prática } \\
\text { profissional/outros) em cada um dos campos de ciências humanas, ciências } \\
\text { sociais e STEM, bem como os diplomas de pós-graduação em um ou mais } \\
\text { campos profissionais. }\end{array}$ \\
\hline
\end{tabular}

\footnotetext{
46 Disponível em: <https://carnegieclassifications.iu.edu/classification_descriptions/grad_program.php>. Acesso em: 7 jul. 2021.

${ }^{47}$ Podemos entender como o mestrado acadêmico do Brasil e que, geralmente, nos EUA concedem o título de Ph.D (Philosophy Doctor).
} 
Espaço Ameríndio

\begin{tabular}{|c|l|}
\hline $\begin{array}{c}\text { Artes e Ciências } \\
\text { (domínio) }\end{array}$ & $\begin{array}{l}\text { concederam mestrado ou doutorado (prática profissional/outros) em algumas } \\
\text { áreas de artes e ciências. Eles também podem conceder mestrado ou não } \\
\text { pesquisa em outros campos, mas em menor número. }\end{array}$ \\
\hline $\begin{array}{c}\text { Educação (domínio) } \\
\text { com Artes e Ciências }\end{array}$ & $\begin{array}{l}\text { concederam mestrado ou doutorado (prática profissional/outros) em artes e } \\
\text { ciências e áreas profissionais, em que o maior número de graus de pós- } \\
\text { graduações foi em educação. }\end{array}$ \\
\hline $\begin{array}{c}\text { Business (domínio) com } \\
\text { Artes e Ciências }\end{array}$ & $\begin{array}{l}\text { concederam mestrado ou doutorado (prática profissional/outros) em artes e } \\
\text { ciências e áreas profissionais em que o maior número de graus de pós- } \\
\text { graduação foi em business. }\end{array}$ \\
\hline $\begin{array}{c}\text { Outros (domínio) com } \\
\text { Artes e Ciências }\end{array}$ & $\begin{array}{l}\text { concederam mestrado ou doutorado (prática profissional/outros) em artes e } \\
\text { ciências e áreas profissionais eem que o maior número de graus de pós- } \\
\text { graduação foi em campo profissional que não em business ou educação. }\end{array}$ \\
\hline $\begin{array}{c}\text { Educação (domínio) } \\
\text { com outros programas } \\
\text { profissionais }\end{array}$ & $\begin{array}{l}\text { concederam mestrado ou doutorado (prática profissional/outros) apenas em } \\
\text { áreas profissionais, e o campo com o maior número de graus de pós-graduação } \\
\text { em educação. }\end{array}$ \\
\hline $\begin{array}{c}\text { Business (domínio) com } \\
\text { outros programas } \\
\text { profissionais }\end{array}$ & $\begin{array}{l}\text { concederam mestrado ou doutorado (prática profissional/outros) apenas em } \\
\text { áreas profissionais, e o campo com o maior número de graus de pós-graduação } \\
\text { em business. }\end{array}$ \\
\hline $\begin{array}{c}\text { Outros (domínio) com } \\
\text { outros programas } \\
\text { profissionais }\end{array}$ & $\begin{array}{l}\text { concederam mestrado ou doutorado (prática profissional/outros) apenas em } \\
\text { áreas profissionais, e o campo com o maior número de graus de pós-graduação } \\
\text { que não em business ou educação. }\end{array}$ \\
\hline
\end{tabular}

Fonte: Portal da Fundação Carnegie ${ }^{48}$

Quadro 3 - Doutorado em Pesquisa

\begin{tabular}{|c|l|}
\hline $\begin{array}{c}\text { Educação } \\
\text { (Programa Único) }\end{array}$ & $\begin{array}{l}\text { concederam doutorado em pesquisa apenas na área de educação, podendo ter } \\
\text { também ofertas de mestrado ou doutorado (prática profissional/outros). }\end{array}$ \\
\hline $\begin{array}{c}\text { Outros } \\
\text { (Programa Único) }\end{array}$ & $\begin{array}{l}\text { concederam doutorado em pesquisa em um único campo que não a educaçáo, } \\
\text { podendo ter ofertas também de mestrado ou doutorado (prática } \\
\text { profissional/outros). }\end{array}$ \\
\hline $\begin{array}{c}\text { Comprehensive } \\
\text { Programs (com Escola } \\
\text { Médica/Veterinária) }\end{array}$ & $\begin{array}{l}\text { concederam doutorado em pesquisa nas áreas das ciências humanas, sociais } \\
\text { e STEM, bem como em medicina, odontologia e medicina veterinária. Eles } \\
\text { podem ter ofertas também de mestrado ou doutorado (prática } \\
\text { profissional/outros). }\end{array}$ \\
\hline $\begin{array}{c}\text { Comprehensive } \\
\text { Mrograms (sem Escola }\end{array}$ & $\begin{array}{l}\text { concederam doutorado em pesquisa nas áreas das ciências humanas, sociais } \\
\text { e STEM, podendo ter ofertas também de mestrado ou doutorado (prática } \\
\text { profissional/outros). }\end{array}$ \\
\hline $\begin{array}{c}\text { Ciências Humanas e } \\
\text { Sociais (domínio) }\end{array}$ & $\begin{array}{l}\text { concederam doutorado em pesquisa em diversas áreas, com o maior número } \\
\text { de doutorados em ciências humanas ou sociais. }\end{array}$ \\
\hline STEM (domínio) & $\begin{array}{l}\text { concederam doutorado em pesquisa em vários campos, com o maior número } \\
\text { de doutorados em pesquisa nos campos STEM. }\end{array}$ \\
\hline Profissional (domínio) & $\begin{array}{l}\text { concederam doutorado em pesquisa em diversas áreas e o maior número } \\
\text { desses doutorados estavam em outras profíssões que não engenharia (como } \\
\text { educação, profissões da saúde, direito, políticas públicas ou serviço social). }\end{array}$ \\
\hline
\end{tabular}

Fonte: Portal da Fundação Carnegie ${ }^{49}$

Assim, a partir desta classificação temos os seguintes números da pós-graduação estadunidense, conforme disposto na tabela 3.

Tabela 3 - Pós-Graduação nos EUA

\begin{tabular}{c|c|c|c|c}
\hline & \multicolumn{2}{|c|}{ Instituições } & \multicolumn{2}{|c}{$\begin{array}{c}\text { Matrículas Outono } \\
2017\end{array}$} \\
\cline { 2 - 5 } & $\mathbf{N}$ & $\%$ & $\mathrm{~N}$ & $\%$ \\
\hline
\end{tabular}

48 Disponível em: <https://carnegieclassifications.iu.edu/classification_descriptions/grad_program.php>. Acesso em: 7 jul. 2021.

49 Disponível em: <https://carnegieclassifications.iu.edu/classification_descriptions/grad_program.php>. Acesso em: 7 jul. 2021. 
Espaço Ameríndio

\begin{tabular}{l|c|c|c|c}
\hline Pós-Bacharelados (não conferem doutorado em pesquisa) & $\mathbf{1 . 3 4 8}$ & $\mathbf{6 6 \%}$ & $\mathbf{4 . 1 3 1 . 4 4 3}$ & $\mathbf{3 4 \%}$ \\
\hline Programa Único & 354 & $17 \%$ & 280.103 & $2 \%$ \\
\hline Foco Profissionais & 457 & $22 \%$ & 866.756 & $7 \%$ \\
\hline Foco Arte e Ciências & 442 & $22 \%$ & 1.879 .657 & $15 \%$ \\
\hline Comprehensive & 95 & $5 \%$ & 1.104 .927 & $9 \%$ \\
\hline Doutorado em Pesquisa / bolsa de estudo & $\mathbf{6 8 6}$ & $\mathbf{3 4 \%}$ & $\mathbf{8 . 0 8 2 . 8 3 3}$ & $\mathbf{6 6 \%}$ \\
\hline Programa Único & 234 & $12 \%$ & 960.095 & $8 \%$ \\
\hline Com Foco & 279 & $14 \%$ & 2.694 .512 & $22 \%$ \\
\hline Comprehensive & 173 & $9 \%$ & 4.428 .226 & $36 \%$ \\
\hline TOTAL & $\mathbf{2 . 0 3 4}$ & & $\mathbf{1 2 . 2 1 4 . 2 7 6}$ & \\
\hline
\end{tabular}

Fonte: Indiana University $(2018$, p. 3) - tradução minha

Conforme destacamos em trabalho anterior:

No mestrado, o estudante passa a maior parte do tempo em aulas, das quais a maioria é seminário, sendo-lhe atribuído o título após a entrega de uma dissertação, para a qual deve realizar um trabalho de investigação ou realizar os exames globais de qualificação (comprehensive exams). As escolas profissionais diferem amplamente nos requisitos de admissão e duração do programa. Estudantes de medicina, por exemplo, geralmente completam um programa de bacharel em estudos pré-médicos em uma faculdade ou universidade antes dos 4 anos de curso em uma escola de medicina. O curso de medicina, que no Brasil é desenvolvido em nível de graduação com sequência em pós-graduação, nos EUA só acontece em termos de pósgraduação. Para entrar na escola de medicina exigemse, além do título de Bachelor (bacharelado), a realização do MCAT (Medical College Admission Test Teste de Admissão à Faculdade de Medicina). Algo semelhante ocorre com a formação de advogados, onde os programas de direito geralmente envolvem 3 anos de curso além do nível de bacharelado. Os requisitos de admissão são um título de Bachelor (bacharel) e o exame LSAT (Law School Admission Test).

O MBA é um curso abrangente de pós-graduação em Administração de Empresas e um complemento muito útil a um título anterior em qualquer especialidade. Para ingressar nesse curso são exigidos o título universitário e o exame admissional.

Algumas universidades estadunidenses consideram 0 título de master como primeiro passo para 0 doutoramento, mas em outras os estudantes podem ser admitidos diretamente sem que Ihes seja exigido o master (semelhante ao que acontece também no Brasil com os programas de Doutorado Direto). Os estudantes que se matriculam em um programa de doutoramento são reconhecidos como candidatos a doutor; assistem a algumas aulas, mas o que 
verdadeiramente os legitima como doutor é o desenvolvimento e defesa de sua própria investigação, a exemplo do que também ocorre no Brasil. (PERALTA, DIAS, GONÇALVES, 2018, p. 972)

Assim, os supramencionados dados apresentam os números de um dos maiores e complexos sistemas educacionais de pós-graduação do mundo, em que - em linhas gerais - se organiza como de formação profissional (destinada a profissões privilegiadas e que ocorrem no âmbito da pós-graduação - como medicina, direito, engenharia, medicina veterinária, etc) ou acadêmica.

No terceiro país mais populoso do mundo, que dispõe de 332.496.990 habitantes (dados do United States Census Bureau ${ }^{50}$ ), aproximadamente $8 \%$ da sua população está na educação superior.

Um sistema que, de acordo com a Fundação Carnegie, congrega $60 \%$ dos alunos matriculados nos programas graduação (sendo $32 \%$ destes alunos matriculados nos cursos das Two-Year Colleges e 68\% nos cursos das instituições de quatro anos) e 40\% nos programas de pósgraduação (sendo 66\% em instituições que dispõe de doutorado em pesquisa). Ou seja, 16\% da população acadêmica estadunidense está nas Two-Year Colleges, sendo parte destes nas Tribal Colleges.

\section{As tribal colleges no sistema educacional estadunidense}

Para DeLong, Monette e Ozaki (2016), as Tribal Colleges são instituições de ensino superior que funcionam em uma mistura de cultura, linguagem, herança, estruturas de clãs e geridas pelas reservas indígenas nas quais estão localizadas. Os autores acrescentam que a primeira instituição foi criada em 1968, sendo agora 37 (32 totalmente credenciados), localizadas em todos os Estados Unidos (vide Figura 4). A maioria das instituições possui cursos de dois anos; apenas sete instituições possuem cursos de quatro anos - consideradas Tribal Universities (em português: Universidades Tribais/Indígenas).

\footnotetext{
${ }^{50}$ Departamento do Censo dos Estados Unidos. Disponível em: <https://www.census.gov/popclock/>. Acesso em: 7 jul. 2021.
} 
Figura 4 - Mapa da Rede das Tribal Colleges e Universities dos EUA

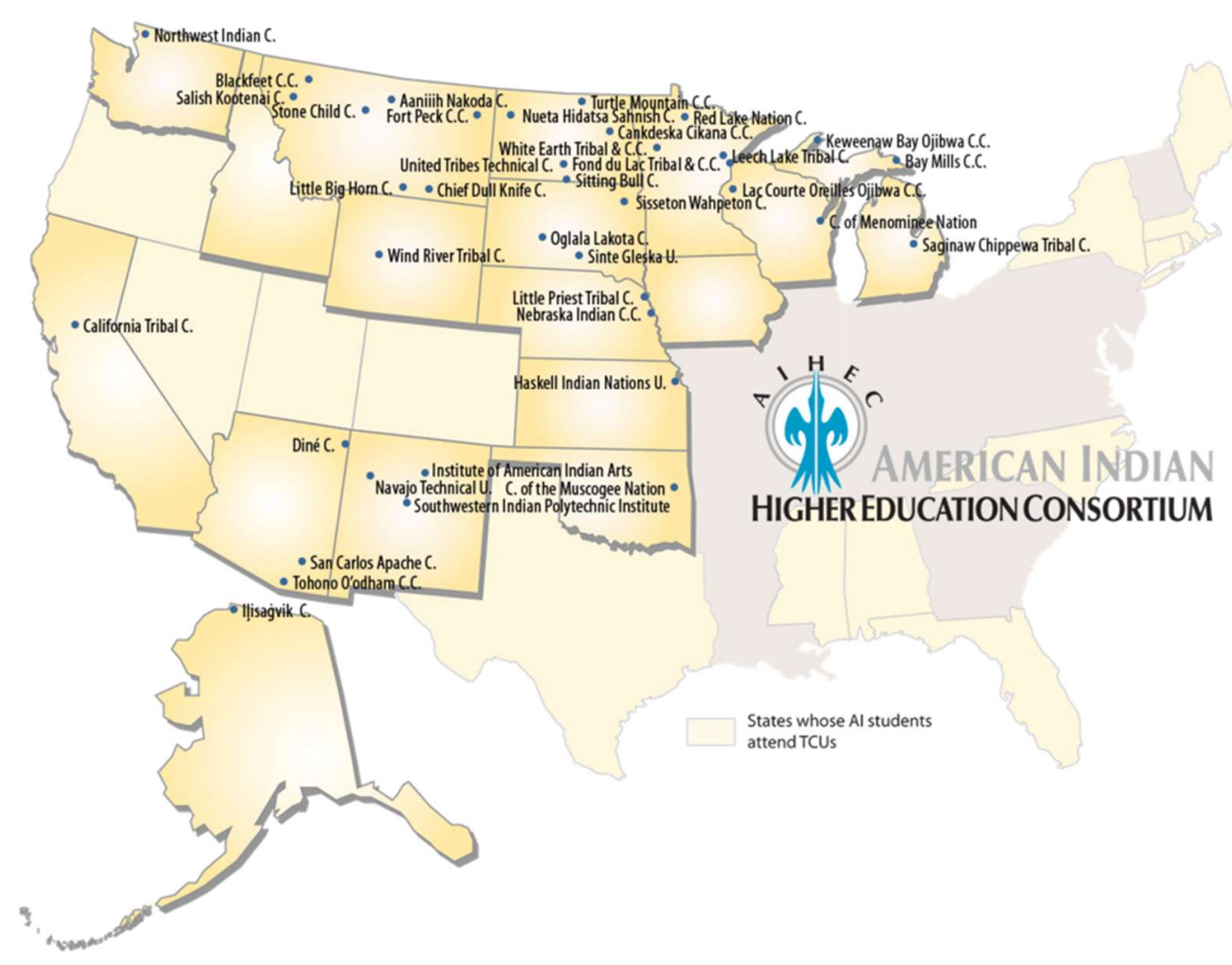

Fonte: site da American Indian Higher Education Consortium (AIHEC) $)^{51}$

As Tribal Colleges (e Universidades) são reguladas pelas nações indígenas das quais fazem parte. Em 1972 foi criado o American Indian Higher Education Consortium (AIHEC, em português: Consórcio de Educação Superior Indígena-Americano) com intuito de representar os interesses destas instituições diante de outras instâncias públicas e privadas, como, por exemplo, o Congresso Nacional. Essas instituições, conforme disposto no mapa da Figura 4, estão localizadas em territórios de reservas indígenas nos Estados Unidos (Figura 5).

${ }^{51}$ Disponível em: <https://www.nasa.gov/education/maianse/awardees>. Acesso em: 7 jul. 2021. 
Figura 5 - Reservas Indígenas nos EUA

Indian Reservations in the Continental United States

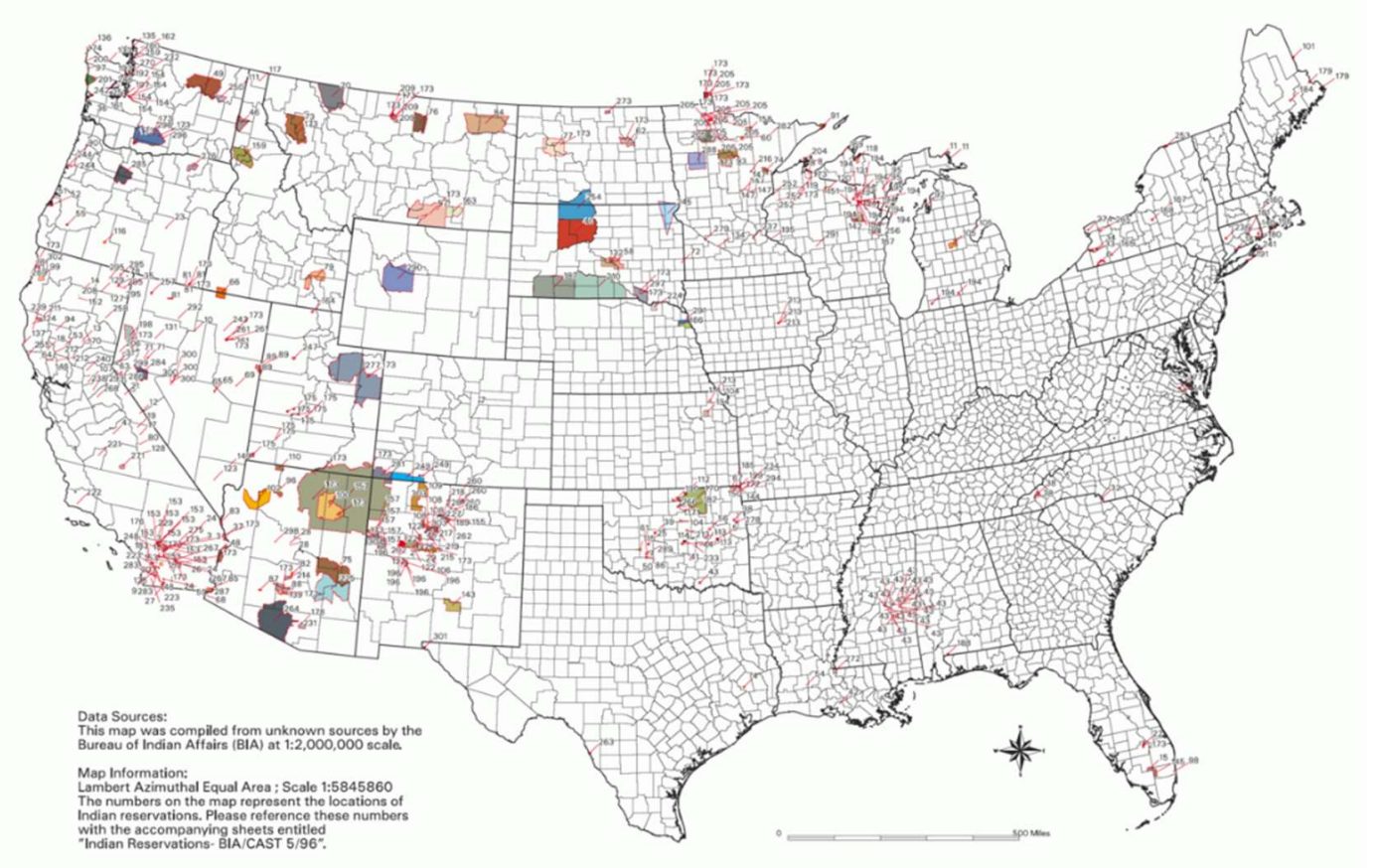

Fonte: site da American Indian Higher Education Consortium (AIHEC) $)^{52}$

Conforme breve análise demográfica apresentada por Norris, Vines e Hoeffel (2012) - a partir do Censo de 2010 dos Estados Unidos - 5,2 milhões de pessoas daquele país se identificaram como "indígena americano e nativo do Alasca" ${ }^{53}$ (universo de 308 milhões); sendo desses, 2,3 milhões se declaram mestiços com outras raças. Assim, mais da metade dessas pessoas (2,9 milhões) se identificam apenas como indígena americano e nativo do Alasca sem miscigenação com outras raças. A análise evidencia que as pessoas que se identificaram como indígena americano e nativo do Alasca miscigenado com outras raças teve um rápido crescimento, aumentando em 39\% desde 2000.

Miller (2020) destaca que nos Estados Unidos existem comunidades indígenas que nunca foram reconhecidos federalmente como nações indígenas - em geral, tal reconhecimento ocorre por meio de tratados, legislação, decisões judiciais, ordens executivas ou ações administrativas. O autor destaca ainda que parte dessas comunidades dispõem de reconhecimento dos estados em que residem; porém, como as comunidades não reconhecidas não dispõem de status federal, elas são inelegíveis para exercer total soberania em relação à sua condição indígena, bem como para acessar programas indígenas federais do Bureau of Indian Affairs ${ }^{54}$ (BIA) e do Indian Health Service ${ }^{55}$. Ou seja, essas

\footnotetext{
${ }^{52}$ Disponível em: < https://www.nasa.gov/education/maianse/awardees>. Acesso em: 7 jul. 2021.

${ }^{53}$ Categoria usada pelo Censo - American Indian and Alaska Native.

${ }^{54}$ Departamento de Assuntos Indígenas.

55 Serviço de Saúde Indígena.
} 
comunidades estão sujeitas à jurisdição civil e criminal estadual e, como resultado, não podem usufruir de certos acordos específicos.

As características étnico-raciais dessas comunidades não reconhecidas variam consideravelmente, sendo algumas semelhantes às "tribos" estereotipadas e outras com características indígenas mais pontuais. Todavia, a maioria dessas comunidades atualmente busca seu reconhecimento âmbito federal para gozar de certos direitos (MILLER, 2020).

Nesse sentido, cabe destacar que algumas das nações indígenas estadunidenses constituem em suas reservas um complexo turístico focado em cassinos - dadas certas prerrogativas legais que desfrutam que mantém a estrutura econômica dessas comunidades. Tomo como exemplo o luxuoso Soaring Eagle Casino \& Resort localizado em Mount Pleasant (Michigan) na reserva indígena da nação Saginaw Chippewa ${ }^{56}$ (figura 6).

Figura 6 - Estrutura do Soaring Eagle Casino \& Resort

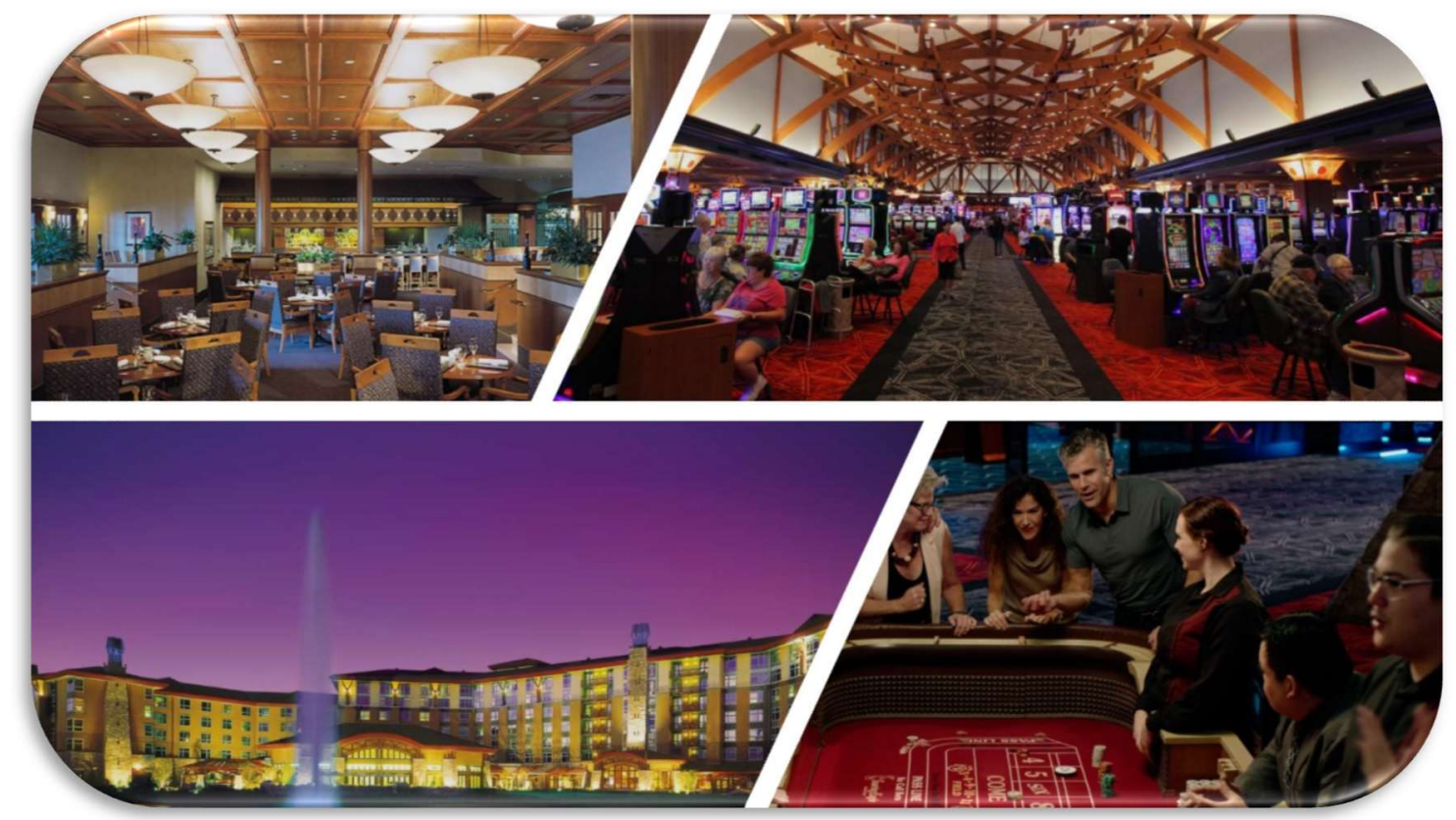

Fonte: site do Soaring Eagle Casino \& Resort ${ }^{57}$

Deste modo, algumas destas comunidades se mantém economicamente a partir destes grandiosos empreendimentos, gerando uma situação econômica - por vezes confortável - para os membros das comunidades e que recai em uma situação que fortalece as iniciativas que promovem o desenvolvimento dessas comunidades, como por exemplo as Tribal Colleges.

Ainda em Miller (2020), embora tenham sido negados status indígenas federais e, consequentemente, acesso a certos programas para

\footnotetext{
${ }^{56}$ Nação indígena federalmente reconhecida e que se encontra dentre as 10 maiores dos Estados Unidos juntamente com Cherokee, Navajo, Choctaw, Mexican American Indian, Sioux, Apache, Blackfeet, Creek, Iroquois - dados do Censo de 2010 (NORRIS; VINES; HOEFFEL, 2012).

${ }^{57}$ Disponível em: $<$ https://www.soaringeaglecasino.com/>. Acesso em: 7 jul. 2021.
} 
comunidades indígenas, certas comunidades não-federais, frequentemente, disponibilizam diversos serviços/programas - dentre eles de trabalho, comércio, justiça saúde e educação - a seus membros de baixa renda. Atualmente, acrescenta o autor, muitas comunidades não reconhecidas estão experimentando um renascimento cultural, servindo como o locus do renascimento indígena em suas regiões, patrocinando powwows $^{58}$ e programas de aprimoramento cultural para jovens e promovendo o orgulho de sua herança indígena.

Neste sentido, as tribal colleges têm papel fundamental para o oferecimento de formação superior a essas comunidades (não reconhecidas) e nações indígenas visando promover uma educação atrelada aos valores desses povos originários advindos de suas heranças culturais, bem como as suas diversas perspectivas socioculturais e econômicas.

Conforme apontam Cunningham e Parker (1998), as Tribal Colleges são instituições que combinam os objetivos tradicionais das community colleges (faculdades comunitárias, pertencente ao CTE) de desenvolvimento econômico local, treinamento de força de trabalho e preparação para educação continuada com uma combinação de apoio suplementar de estudantes, preservação e aprimoramento cultural e programas de divulgação comunitária.

Chelberg e Lisa Bosman (2020) destacam a importância da rede das Tribal Colleges para permanência de estudantes indígenas nos estudos pós-secundários/superiores, dadas as desigualdades presentes nas instituições não indígenas, mesmo essas instituições dispondo de tentativas significativas de matrículas e manutenção desses estudantes em tal nível de ensino. As autoras identificaram, a partir de outros estudos, algumas barreiras enfrentadas pelos estudantes indígenas em instituições não-indígenas dos Estados Unidos: “(...) interpessoais (por exemplo, sentimentos de inferioridade e isolamento), desafios para obter os recursos necessários no nível institucional (por exemplo, informações sobre ajuda financeira) e exibições evidentes de racismo e discriminação no campus (...)" (CHELBERG; BOSMAN, 2020, p. 1, tradução minha).

Desse modo, o fortalecimento desta rede de ensino naquele país é essencial para o acesso de estudantes indígenas dos Estados Unidos nos estudos pós-secundários a partir de uma proposta que lida com os aspectos interculturais pautados na(s) cultura(s) indígena. Conforme já apontamos, estas instituições dispõem de programas de apoio financeiro que garantem a permanência desses estudantes indígenas em sua rede viabilizando sua formação pós-secundária/superior.

Para este texto discutiremos a estrutura do Saginaw Chippewa Tribal College (SCTC), localizada na cidade de Mount Pleasant (estado de Michigan) no condado de Isabella; tal instituição oferece educação superior/pós-secundária e vocacional às comunidades indígenas. A cidade de Mount Pleasant dispõe de uma reserva indígena - base de terra da nação indígena Saginaw Chippewa.

\footnotetext{
${ }^{58}$ Reunião de povos nativos da América do Norte. Disponível em: $<$ https://www.powwows.com/>. Acesso em: 7 jul. 2021.
} 
Conforme consta no portal da instituição ${ }^{59}$, a SCTC foi fundada em 1998 e em 2007 tornou-se uma instituição de ensino superior devidamente credenciada ao sistema estadunidense. A instituição tem como missão "oferecer oportunidades educacionais que refletem os valores Anishinaabe".

O texto Native American Traditions: Anishinaabe Ojibwe Ways ${ }^{60}-$ "Projeto O Pluralismo" da Universidade de Havard ${ }^{61}$ - descreve que os ojibwe, também conhecidos como Chippewa, referem-se a si mesmos em sua língua original como Anishinaabe ou "o povo". Chegando a mais de 78.000 nos Estados Unidos, os ojibwas são formados por redes independentes, unidos por uma língua, cultura e sistema de clã tradicional compartilhados e tradicionalmente habitam a região dos Grandes Lagos Ocidentais de Michigan, Wisconsin, Minnesota, North Dakota, Ontario e Manitoba. Os Anishinaabe estão culturalmente relacionados a outros povos da floresta do nordeste dos EUA e linguisticamente relacionados a outros povos da família de línguas Algonkian.

O supramencionado documento do "Projeto O Pluralismo" afirma ainda que a religiosidade objibwa tem a ver com as histórias e cerimônias que fazem conexões entre as pessoas e as fontes de vida. Tem ainda como valores o respeito aos mais velhos e o compromisso ético com a vida da comunidade. A tradição religiosa ojibwe enfatiza a importância da dedicação ao longo da vida à harmonia e beleza de bimaadiziwin, o movimento circular contínuo da vida.

Assim, a SCTC, substanciado na cultura Anishinaabe, incorpora os "ensinamentos dos Sete Avôs" (Seven Grandfather teachings): Verdade Debwewin; Sabedoria - Nbwaakaawin; Bravura - Aakwa'ode'ewin; Humildade - Dbaadendiziwin; Respeito - Mnaadendimowin; Amor Zaagidwin; Honestidade - Gwekwaadziwin (figura 7). Valorizando e fortalecendo, assim, a ancestralidade.

Figura 7 - Logomarca e valores do SCTC

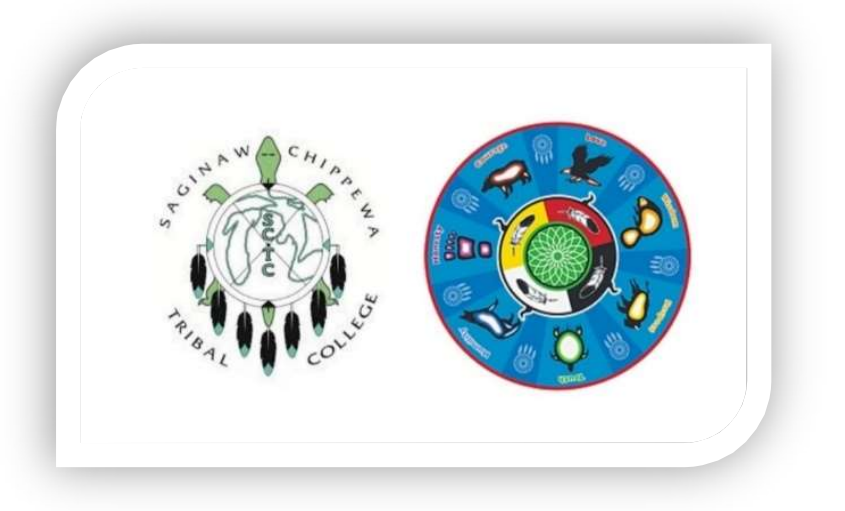

Fonte: site da SCTC ${ }^{62}$

\footnotetext{
${ }^{59}$ Disponível em: <https://www.sagchip.edu/our-history>. Acesso em: 7 jul. 2021.

${ }^{60}$ Em português: Tradições Nativas Americanas: Modos Anishinaabe Ojibwe (tradução livre).

${ }^{61}$ Disponível em $<$ https://pluralism.org/files/pluralism/files/anishinaabe_ojibwe_ways.pdf $>$. Acesso em: 7 jul. 2021.

${ }^{62}$ Disponível em: <https://www.sagchip.edu/>. Acesso em: 7 jul. 2021.
} 
Ao constituir sua visão institucional a SCTC dispõe da seguinte redação "manter um ambiente estimulante que inspire as pessoas a atingir um nível mais alto de sucesso pessoal e acadêmico" - a meu ver centrado em uma racionalidade instrumental de instituição de ensino, aquém dos elementos culturais e identitários que se fazem presentes na sua missão e valores.

Assim, a missão e valores institucionais aparentam ser pontos nevrálgicos e paradoxais, visto que buscam alcançar os valores culturais propostos para o fortalecimento identitário destas nações indígenas, embora sigam aspectos pautados em uma perspectiva econômica neoliberal fortemente presente na cultura meritocrática estadunidense.

Doravante, os currículos dos cursos oferecidos são construídos pensando cada formação e seus respectivos componentes curriculares a partir da missão, valores e visão institucionais da SCTC.

Atualmente, a instituição dispõe de quatro programas de formação - todos de natureza acadêmica ${ }^{63}$ :

Estudos Nativo Americanos - NAS $(A A) \rightarrow$ ajudar os alunos a obterem o grau NAS por meio de um estudo intensivo dos Anishinaabek e de outros povos indígenas de perspectivas históricas e contemporâneas.

$\checkmark$ Business $(\mathrm{AA}) \rightarrow$ preparar nossos alunos para carreiras de negócios de sucesso em todos os setores e / ou prepará-los para a transferência para um programa de graduação de quatro anos.

$\checkmark$ Ciências Gerais $(A S) \rightarrow$ preparar os alunos com uma base sólida em ciências e matemática, permitindo assim que o aluno tenha a oportunidade de se transferir para uma universidade de quatro anos em busca de um diploma de bacharelado, entrar em outro programa de faculdade ou obter emprego em uma carreira relacionada à ciência.

$\checkmark$ Artes Liberais $(A A) \rightarrow$ preparar os alunos para demonstrar competência no trabalho do curso em várias disciplinas e prepará-los para transferência para um programa de graduação de quatro anos, adquirir as habilidades necessárias para entrar na força de trabalho do século 21 e/ou ajudá-lo ou a se tornar um cidadão socialmente responsável.

Conforme observado na missão de cada um dos programas, três deles deixam evidente o direcionamento dos cursos para transferência semelhante às Community Colleges tradicionais. O NAS, apesar de não explicitar tal expectativa em sua missão, por não ser uma formação vocacional e se tratar de uma formação AA, também dispõe de uma formação destinada a uma possível transferência, talvez para uma

\footnotetext{
${ }^{63}$ Conforme apontei anteriormente, os programas acadêmicos visam a transferência dos estudantes para complementar seus estudos em instituições de quatro anos nos cursos de bacharelado.
} 
Espaço Ameríndio

formação em bacharelado mais específica como, por exemplo, Antropologia.

Algo notório observados em todos os quatro programas é que seus objetivos são construídos a partir de três perspectivas: Comunicação; Pensamento Crítico; Conscientização e Apreciação Cultural - de acordo com o quadro 4.

Quadro 4 - Objetivos dos Programas de Formação da SCTC

\begin{tabular}{|c|c|c|c|c|}
\hline & $\begin{array}{c}\text { ESTUDOS NATIVO } \\
\text { AMERICANOS } \\
\end{array}$ & BUSSINESS & $\begin{array}{c}\text { CIÊNCIAS } \\
\text { GERAIS }\end{array}$ & $\begin{array}{c}\text { ARTES } \\
\text { LIBERAIS }\end{array}$ \\
\hline Comunicação & $\begin{array}{l}\text { Expressar e trocar } \\
\text { ideias por meio de } \\
\text { comunicação } \\
\text { escrita e oral; }\end{array}$ & $\begin{array}{l}\text { Mostrar } \\
\text { habilidades } \\
\text { profissionais em } \\
\text { comunicação; }\end{array}$ & $\begin{array}{l}\text { Avaliar métodos } \\
\text { científicos, } \\
\text { dados e } \\
\text { conclusões em } \\
\text { várias } \\
\text { disciplinas; }\end{array}$ & $\begin{array}{l}\text { Identificar, } \\
\text { avaliar e } \\
\text { comunicar com } \\
\text { eficácia várias } \\
\text { ideias nas } \\
\text { disciplinas de } \\
\text { artes liberais; }\end{array}$ \\
\hline $\begin{array}{c}\text { Pensamento } \\
\text { Crítico }\end{array}$ & $\begin{array}{l}\text { Analisar as } \\
\text { questões } \\
\text { contemporâneas e } \\
\text { culturais dos Povos } \\
\text { Indígenas; }\end{array}$ & $\begin{array}{l}\text { Identificar a } \\
\text { aplicação } \\
\text { prática dos } \\
\text { princípios de } \\
\text { negócios para } \\
\text { orientar a } \\
\text { tomada de } \\
\text { decisão } \\
\text { gerencial; }\end{array}$ & $\begin{array}{l}\text { Analisar dados } \\
\text { usando o } \\
\text { método } \\
\text { científico e } \\
\text { técnicas de } \\
\text { análise } \\
\text { estatística para } \\
\text { desenvolver } \\
\text { opiniões } \\
\text { informadas } \\
\text { sobre questões } \\
\text { sociais com uma } \\
\text { componente } \\
\text { científica; }\end{array}$ & $\begin{array}{l}\text { Demonstrar } \\
\text { pensamento } \\
\text { crítico e } \\
\text { habilidades de } \\
\text { análise nas } \\
\text { disciplinas de } \\
\text { artes liberais; }\end{array}$ \\
\hline $\begin{array}{l}\text { Conscientização e } \\
\text { Apreciação Cultural }\end{array}$ & $\begin{array}{l}\text { Demonstrar } \\
\text { conhecimento das } \\
\text { diversas } \\
\text { perspectivas } \\
\frac{\text { culturais de }}{\text { Anishinaabek e }} \\
\begin{array}{l}\text { outros povos } \\
\text { indígenas; }\end{array} \\
\frac{\text { Demonstrar }}{\text { proficiência }} \\
\frac{\text { elementar em }}{\text { Anishinaabemowin. }}\end{array}$ & 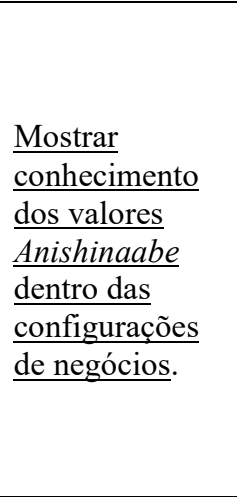 & $\begin{array}{l}\frac{\text { Comparar e }}{\text { contraste as }} \\
\text { perspectivas } \\
\underline{\text { científicas }} \\
\underline{\text { ocidentais e }} \\
\underline{\text { indígenas para }} \\
\underline{\text { relacionar seu }} \\
\underline{\text { conhecimento }} \\
\underline{\text { científico aos }} \\
\underline{\text { mundos naturais }} \\
\underline{\text { e tecnológicos }} \\
\underline{\text { ao seu redor. }}\end{array}$ & $\begin{array}{l}\text { Reconhecer sua } \\
\text { responsabilidade } \\
\text { cívica dentro da } \\
\text { comunidade e da } \\
\text { sociedade em } \\
\text { geral. }\end{array}$ \\
\hline
\end{tabular}

Fonte: site da SCTC ${ }^{64}$

No quadro 4 foram sublinhados aqueles objetivos que dispõe de especificidade no fortalecimento dos valores culturais indígenas - sendo a maioria deles no NAS demonstrando que, dentre os quatros programas de formação, apenas um foca em tal problematização das questões indígenas. Todavia, na perspectiva Conscientização e Apreciação Cultural, as questões indígenas são apontadas diretamente em três dos quatros programas.

\footnotetext{
${ }^{64}$ Disponível em: <https://www.sagchip.edu/>. Acesso em: 7 jul. 2021.
} 
Espaço Ameríndio

\section{Para fins de ilustração, destaco no quadro 5 a organização curricular dos programas de formação.}

\section{Quadro 5 - Estrutura Curricular dos Programas da SCTC}

\begin{tabular}{|c|c|c|}
\hline & OBRIGATÓRIOS & ELETIVOS \\
\hline $\begin{array}{c}\text { Estudos Nativo } \\
\text { Americanos } \\
\text { (62 créditos exigidos, sendo no } \\
\text { mínimo } 19 \text { obrigatórios e } 12 \\
\text { eletivos) }\end{array}$ & $\begin{aligned} \Rightarrow & \text { Introdução à Tecnologia da } \\
& \text { Computação (3) } \\
\Rightarrow & \text { Língua Ojibwe I e II (3 - cada) } \\
\Rightarrow & \text { Legislação e Política dos Nativos } \\
& \text { Americanos (3) } \\
\Rightarrow & \text { Pesquisa da História dos Nativos } \\
& \text { Americanos (3) } \\
\Rightarrow & \text { Globalização (3) } \\
\Rightarrow & \text { Seminário de Pós-Graduação (1) }\end{aligned}$ & $\begin{aligned} \Rightarrow & \text { Beadwork }^{65} \text { I e II (3 - cada) } \\
\Rightarrow & \text { Plantas e Medicina dos Nativos } \\
& \text { Americanos I e II (3 - cada) } \\
\Rightarrow & \text { Língua Ojibwe III e IV (3 - cada) } \\
\Rightarrow & \text { Arte Anishinaabe (3) } \\
\Rightarrow & \text { Arte Contemporânea Nativo } \\
& \text { Americana (3) } \\
\Rightarrow & \text { História Anishinaabe: } 1600 \text { até o } \\
& \text { presente (3) } \\
\Rightarrow & \text { História Anishinaabe: Começos } \\
& \text { até } 1600 \text { (3) } \\
\Rightarrow & \text { Religião Nativo Americana (33) } \\
\Rightarrow & \text { Pesquisa de Estudos Nativos } \\
& \text { Americanos (3) } \\
\Rightarrow & \text { Artesanato Anishinaabe (3) } \\
\Rightarrow & \text { Questões Ambientais dos Nativos } \\
& \text { Americanos (3) } \\
\Rightarrow & \text { Recuperando e revitalizando } \\
& \text { Anishinaabemowin (3) } \\
\Rightarrow & \text { Tópicos Especiais em Estudos } \\
& \text { Nativo-Americanos (3) }\end{aligned}$ \\
\hline $\begin{array}{c}\text { Bussiness } \\
\text { (62 créditos exigidos, sendo no } \\
\text { mínimo } 28 \text { obrigatórios e } 03 \\
\text { eletivos) }\end{array}$ & $\begin{array}{l}\Rightarrow \text { Contabilidade Financeira (3) } \\
\Rightarrow \text { Contabilidade Gerencial (3) } \\
\Rightarrow \text { Introdução ao Bussiness (3) } \\
\Rightarrow \text { Direito Empresarial (3) } \\
\Rightarrow \text { Princípios de Gestão (3) } \\
\Rightarrow \text { Princípios de Marketing (3) } \\
\Rightarrow \text { Comunicação Empresarial (3) } \\
\Rightarrow \text { Introdução a Computadores (3) } \\
\Rightarrow \text { Princípios de Macroeconomia (3) } \\
\Rightarrow \text { Seminário de Pós-Graduação (1) }\end{array}$ & $\begin{array}{l}\Rightarrow \text { Finanças Pessoais (3) } \\
\Rightarrow \text { Gestão de Recursos Humanos (3) } \\
\Rightarrow \text { Tópicos Especiais de Bussines (3) } \\
\Rightarrow \text { Princípios de Microeconomia (3) } \\
\Rightarrow \text { Cálculo de Negócios (4) } \\
\Rightarrow \text { Introdução à Estatística (3) }\end{array}$ \\
\hline $\begin{array}{c}\text { Ciências Gerais } \\
\text { (62 créditos exigidos, sendo no } \\
\text { mínimo } 20 \text { obrigatórios e } 13 \\
\text { eletivos) }\end{array}$ & $\begin{aligned} \Rightarrow & \text { Língua Ojibwe I (3) ou Língua } \\
& \text { Espanhola I (3) } \\
\Rightarrow & \text { Introdução a Computadores (3) } \\
\Rightarrow & \text { Pré-cálculo (4) } \\
\Rightarrow & \text { Introdução à Biologia (3) } \\
\Rightarrow & \text { Laboratório de Biologia (2) } \\
\Rightarrow & \text { Álgebra intermediária (4) (ou } \\
& \text { ciência / matemática eletiva se } \\
& \text { aprovado pelo orientador) } \\
\Rightarrow & \text { Seminário de Pós-Graduação (1) }\end{aligned}$ & $\begin{aligned} \Rightarrow & \text { Astronomia } 110(3) \text { e Astronomia } \\
& 110 \mathrm{~A}(2) \\
\Rightarrow & \text { Biologia } 216(3) \text { e Biologia 216A } \\
& (2) \\
\Rightarrow & \text { Química } 105 \text { (3) e Química 105A } \\
& (2) \\
\Rightarrow & \text { Ciência Ambiental 120 (3) e } \\
& \text { Ciência Ambiental 120A (2) } \\
\Rightarrow & \text { Geologia 101 (5) } \\
\Rightarrow & \text { Geografia 201 (5) } \\
\Rightarrow & \text { Física 101 (3) e Física 101A (2) }\end{aligned}$ \\
\hline $\begin{array}{c}\text { Artes Liberais } \\
\text { (62 créditos exigidos, sendo no } \\
\text { mínimo } 13 \text { obrigatórios e } 18 \\
\text { eletivos) }\end{array}$ & $\begin{array}{l}\text { Introdução à Literatura (3) } \\
\text { Governo Americano (3) } \\
\text { Introdução a Computadores (3) } \\
\Rightarrow \text { Língua Ojibwe I (3) ou Língua } \\
\text { Espanhola I (3) } \\
\text { Seminário de Pós-Graduação (1) }\end{array}$ & $\begin{array}{l}\text { Eletiva de História (3) } \\
\text { Eletiva de Ciências (3) } \\
\text { Eletiva de Ciências Sociais (3) } \\
1 \text { Eletiva - Qualquer disciplina (nível } \\
100 \text { ou 200) (3) } \\
2 \text { Eletivas - Qualquer disciplina } \\
\text { (nível 200) (6) }\end{array}$ \\
\hline
\end{tabular}

\footnotetext{
${ }^{65}$ Miçangas.
} 
Além dos créditos do quadro 5, o aluno deverá cursar os requisitos (31 créditos) de Educação Geral ${ }^{67}$ para conclusão do programa escolhido. São eles: [i] Língua Inglesa - 9 créditos: Inglês 102 e 103 (3 créditos cada) e inglês (oratória) 130 (3 créditos); [ii] Ciência - 10 créditos: duas disciplinas ( 3 créditos cada) com requisitos laboratoriais e duas disciplinas (mínimo de 4 créditos) em Biologia, Química, Geologia, Ciências Ambientais, Física ou Astronomia; [iii] Ciências Sociais Psicologia da Aprendizagem (3 créditos); [iv] Matemática - Raciocínio Quantitativo (3 créditos) ou outra disciplina superior; [v] Estudos Nativos Americanos - 6 créditos: História Anishinaabe: Começos até 1600 (3 créditos) ou História Anishinaabe: 1600 até o presente (3 créditos) e Problemas Nativos Americanos Contemporâneos (3 créditos).

\section{Considerações finais}

Investigar a rede das Tribal Colleges estadunidense foi importante para a compreensão do significado destas instituições para os povos nativos daquele país, possibilitando-nos entender a interface de tal rede com o seu sistema educacional.

$\mathrm{Na}$ caracterização do sistema educacional dos Estados Unidos, observamos alinhamentos das formações das Community Colleges, consequentemente das Tribal Colleges, com os cursos bacharelado (programas de transferência) - considerando essas instituições como meio de acesso às universidades.

Ao analisar estas instituições, observa-se que elas são concebidas para fins de promoção dos valores culturais das populações indígenas visando o fortalecimento da identidade dos nativos estadunidenses; todavia, ao se analisar os documentos institucionais da STCT, nota-se um aparente paradoxo no que tange à relação desta com o supramencionado processo de transferência para cursos de bacharelado em universidades, submetendo-se, por vezes, a valores estadunidenses preconizados por uma política econômica de ordem neoliberal típica dos Estados Unidos.

Dos quatros programas ofertados pela instituição, apenas um dispõe de uma lógica específica de formação voltada para história e cultura indígenas, apesar de os demais programas apresentarem poucos componentes curriculares que problematizam questões dos povos nativos americanos.

Considerando que o sistema universitário estadunidense é pago, outro aspecto a se destacar é que parte dos alunos que procuram as tribal colleges se inserem em tal rede por questões econômicas em detrimento de questões culturais voltadas aos povos nativos americanos, pois seus programas são $85 \%$ mais baratos que aqueles cobrados pelas

\footnotetext{
${ }^{66}$ Disponível em: $<$ https://www.sagchip.edu/science>. Acesso em: 7 jul. 2021.

${ }_{67} \quad$ Disponível em: $\quad<$ https://501c1794-a5f9-4e92-975b98ea9a434fa0.filesusr.com/ugd/0d99a3_b60a035573f24510a1946b2a485f9185.pdf>. Acesso em: 7 jul. 2021.
} 
universidades. Assim, considerando tal lógica, é que, possivelmente, a disposição curricular dos programas é construída, visto que as disciplinas são codificadas, a partir daquelas já existentes nas universidades, visando alinhamento curricular das mesmas, vislumbrando uma possível futura transferência para os cursos de bacharelado - situação semelhante a que acontece (e relatada neste artigo) nos Community Colleges.

Outros pontos carecem de melhor análise: como são os financiamentos dos estudantes indígenas nas tribal colleges? Quais impactos da formação destas instituições na condição socioeconômica destes alunos? Qual perfil dos professores que trabalham nestas instituições? Caso esses professores não sejam indígenas, como lidam com aspectos interculturais? Como ocorre o processo de transferência destes alunos para as universidades? Como componentes curriculares atribuem significados culturais aos seus conteúdos? Enfim, questões que nos foram limitadas neste estudo e que poderão servir para problematizações/provocações em investigações posteriores. 
Espaço Ameríndio

\section{Referências bibliográficas}

AMERICAN INDIAN HIGHER EDUCATION CONSORTIUM (AIHEC). Tribal colleges:

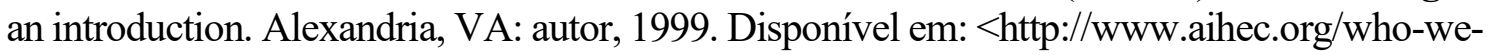
serve/docs/TCU_intro.pdf $>$. Acesso em: 26 out. 2018.

CHELBERG, Kelli; BOSMAN, Lisa. American indian college student mentoring: a study to measure changes in self- eficacy. Education Sciences. V. 10, n. 2. p.1-13, 2020. Disponível em: <https://www.mdpi.com/2227-7102/10/2/38>. Acesso em: 07 jul. 2021.

DAMATTA, Roberto. Relativizando: uma introdução à antropologia social. Rio de Janeiro: Rocco, 2010.

DELONG, Loretta M.; MONETTE, Gerald E.; OZAKI, C. Casey. Nurturing student success in Tribal Colleges. New directions for community colleges, v. 2016, p. 45-56. 2016.

GHISOLFI, Juliana Couto. Políticas de educação superior norte-americanas: faça o que eu digo mas não faça o que eu faço? São Paulo: Cortez, 2004.

GONÇALVES, Harryson Júnio Lessa; DIAS, Ana Lúcia Braz; PERALTA, Deise Aparecida. Estudo Comparativo sobre o Ensino de Matemática em Currículos de Educação Profissional Técnica: Brasil e Estados Unidos. Boletim de educação matemática (Bolema). Rio Claro, v. 32, p. 31-56, 2018.

GORDON, Howard R. D. The History and Growth of Career and Technical Education in America. Long Grove: Waveland Press, Inc., 2014.

INDIANA UNIVERSITY. Center for Postsecondary Research. The Carnegie Classification of Institutions of Higher Education: 2018 edition (Based on Classifications as of May 24, 2019 - Revision 7). Bloomington, IN: Indiana University, 2018. Disponível em: <https://carnegieclassifications.iu.edu/>. Acesso em: 7 jul. 2021.

LAPLANTINE, François. Aprender antropologia. São Paulo: Brasiliense, 2003.

MILLER, Mark Edwin. (2020). Non-Recognized Tribes. In The American Mosaic: The American Indian Experience. Disponível em: <http://americanindian.abcclio.com/Search/Display/1572075>. Acesso em: 7 jul. 2021.

NORRIS, Tina; VINES, Paula L; HOEFFEL, Elizabeth M. The American Indian and Alaska Native Population: 2010. January 2012. Disponível em: $<$ https://www.census.gov/history/pdf/c2010br-10.pdf $>$. Acesso em: 7 jul. 2021.

PARKER, Christina. Tribal colleges as community institutions and resources. New directions for higher education, n. 102, p. 45-56, 1998.

PERALTA, Deise Aparecida; DIAS, Ana Lúcia Braz; GONÇALVES, Harryson Júnio Lessa. Educação Profissional nos EUA: traços históricos, legais e curriculares. Educação e Realidade, v. 43, p. 969-987, 2018. Disponível em: 
Espaço Ameríndio

$<$ https://www.scielo.br/scielo.php?script=sci arttext\&pid=S2175-

62362018000300969>. Acesso em: 07 jul. 2021.

Recebido em: 07/07/2021* Aprovado em: 09/08/2021 * Publicado em: 30/08/2021 